TITLE:

\title{
Development and validation of a physics-based urban fire spread model
}

AUTHOR(S):

HIMOTO, Keisuke; TANAKA, Takeyoshi

CITATION:

HIMOTO, Keisuke ...[et al]. Development and validation of a physics-

based urban fire spread model. Fire Safety Journal 2008, 43(7): 477-494

ISSUE DATE:

2008-10

URL:

http://hdl.handle.net/2433/93452

RIGHT:

Copyright (c) 2007 Elsevier Ltd; This is not the published version. Please cite only the published version.; この論文は出版社版でありません。引 用の際には出版社版をご確認ご利用ください。 


\section{Development and Validation of A Physics-based Urban Fire Spread Model}

Keisuke HIMOTO (corresponding author)

e-mail: keisuke.himoto@kupru.iae.kyoto-u.ac.jp

tel: $+81-(0) 774-38-4481$

fax: $+81-(0) 774-38-4044$

Pioneering Research Unit for Next Generation, Kyoto University

Gokasho, Uji, Kyoto 611-0011, Japan

Takeyoshi TANAKA

Disaster Prevention Research Institute, Kyoto University

Gokasho, Uji, Kyoto 611-0011, Japan

\section{ABSTRACT}

A computational model for fire spread in a densly-built urban area is developed. The model is distinct from existing models in that it explicitly describes fire spread phenomena with physics-based knowledge achieved in the field of fire safety engineering. In the model, urban 
fire is interpreted as an ensemble of multiple building fires, that is, the fire spread is simulated by predicting behaviors of individual building fires under the thermal influence of neighboring building fires. Adopted numerical technique for the prediction of individual building fire behavior is based on the one-layer zone model. Governing equations of mass, energy, and chemical species in component rooms are solved simultaneously, for the development of temperature, concentrations of chemical species, and other properties. As for the building-to-building fire spread, three characteristic phenomena are considered as contributing factors, i.e.: (I) thermal radiation from fire involved buildings; (II) temperature rise due to wind-blown fire plumes; and (III) firebrand spotting. As for the model verification, fire spread simulations were carried out in a hypothetical urban area, where 2,500 buildings of identical configuration were aligned at constant separations. Calculated fire spread rates were then compared with that of the Hamada-model, and reasonable agreements were obtained. The model was further verified with the record of a past urban fire which took place in the city of Sakata in 1976. Although the general features of the fire spread were similar, there were certain discrepancies in the eventual burnt area. The reasons for these discrepancies were discussed and issues for future refinements were stated.

Keywords: Urban fire; Fire Spread; External flame; Fire plume; Firebrand; Zone model 


\section{INTRODUCTION}

When a fire initiates in a densely-built urban area, it easily propagates to adjacent buildings one after another. Especially in the case of large earthquake, when multiple fires break out simultaneously, the hazard of fire spread is likely to overwhelm the ability of fire fighting and enlarge the damaged area. Such urban fire involves as many as thousands or even more building fires at a time. Historically, cities especially in the United States and Japan have frequently experienced such fires and have suffered substantial damage. Ones of the well known urban fires are as follow [1-4]: Chicago Fire (1871), which lasted for 3 days, burnt over 17,000 buildings and caused 300 fatalities; San Francisco Earthquake Fire (1906) burnt area of 1,200,000 $\mathrm{m}^{2}$ and caused 700 fatalities; Kanto-Earthquake Fire (1926) burnt area of $38,000,000 \mathrm{~m}^{2}$, in which almost $70 \%$ of buildings existed in the city area were destroyed, and caused over 100,000 fatalities mostly by fire; Hakodate Fire (1934), in which the rate of fire spread reached as fast as $1,000 \mathrm{~m} /$ hour due to spotting of numerous firebrands, burnt 23,000 buildings and caused 2,100 fatalities; Sakata Fire (1976) burnt 1,700 buildings in spite of considerable effort made by fire fighters; Oakland Hills Fire (1991), which took place at the urban/wildland interface, burnt over 2,300 buildings; and Hanshin-Awaji Earthquake Fire (1995), which involved concurrent fires in multiple places, burnt 7,000 buildings in total and 
caused 500 fatalities.

Several attempts have been made in developing models for prediction of urban fire spread behaviors. Such a model was firstly proposed by Hamada in 1951 [4,5], in which the rate of fire spread was formulated empirically as functions of macroscopic parameters of the environment such as wind speed, building scale, building-to-building separation, construction types, etc.. The model was designed to take a form of a system of algebraic equations, so that it can calculate the rate of fire spread without an aid of numerical computation. Accuracy of the model was supplemented by adjusting the involved empirical constants so that the simulated fire spread rate agrees well with that of the past incidents. Basic concepts of the models developed later on are similar to those of the Hamada model, in which they describe the macroscopic behaviors of fire spread with empirical relations [4,6-12]. The advantage of such an approach of modeling is that it can simulate the rate of fire spread with a fairly simple procedure. However, as fire spread mechanisms are not explicitly incorporated in these models, there are difficulties in evaluating the hazard of fire spread quantitatively as a function of a variety of factors involved. As a result, they have not always been made efficient use of designing countermeasures.

So the purpose of this study is to develop a quantitative model for urban fire spread, with the physics-based knowledge of the phenomena, to explore effective solutions to the above problem. A number of attempts have been made for the identical purpose in the last few years $[13,14]$. 
This paper rearranged the recent development of the author's model and carried out a number of simulations for the model verification.

\section{OUTLINE OF THE URBAN FIRE SPREAD MODEL}

Schematic diagram of the present model is shown in Fig.1. In the model, spread of fire in urban area is described by simulating the behaviors of individual building fires under the influence of neighboring building fires, as urban fire is nothing but an ensemble of multiple building fires. Thus the model consists of two major sub-models: one that describes fire behaviors inside buildings; and another that describes building-to-building fire spread.

As to the building fire model, each room of a building is considered as a control volume with uniform physical properties, and transient development of internal fire behaviors are calculated by solving the governing equations for the properties of control volumes simultaneously. This uniformity assumption is appropriate as vigorous phase of fire occupies a large portion of compartment fires, and building-to-building fire spread takes place mostly within this particular phase. Such an approach is generally called zone modeling, which is widely adopted in building fire safety engineering. A reliable fire spread model will effectively be developed by extending such established numerical techniques.

As to the building-to-building fire spread, following mechanisms are considered as 
contributing factors:

(I) thermal radiation heat transfer from fire involved buildings;

(II) temperature rise due to wind-blown fire plumes;

(III) spotting of fire brands to the downwind of fire involved buildings.

As an urban area is composed of substantial number of buildings in general, it is indispensable to minimize the load of fire spread computation. Thus, we adopt experimentally verified similarity relations for the prediction of these phenomena, instead of taking fine modeling approach such as CFD techniques. Under the influence of the above phenomena, occurrence of fire spread is determined when one of the following conditions are met:
(A) incident heat flux through opening exceeds a critical value $\dot{q}_{c r}^{\prime \prime}$;
(B) surface temperature of exterior wooden wall exceeds a critical value $T_{c r}$;
(C) firebrands at high energy states are fallen upon combustibles.

\section{BUILDING FIRE MODEL}

\subsection{Governing Equations}

Following the definition of the one layer zone model, a room of building is assumed as a control volume in which the properties of compartment gases are uniform regardless of spatial position. Then the conservation equations of mass, energy, and chemical species (the subscripts 
$O$ and $F$ denote oxygen and gasified fuel, respectively) for an arbitrary control volume is

expressed as follows, respectively,

$\frac{d}{d t}\left(\rho_{i} V_{i}\right)=\dot{m}_{F, i}-\sum_{j}\left(\dot{m}_{i j}-\dot{m}_{j i}\right)$

$\frac{d}{d t}\left(c_{P} \rho_{i} T_{i} V_{i}\right)=\left(\dot{Q}_{B, i}+c_{P} \dot{m}_{F, i} T_{P}\right)-\left\{\sum \dot{Q}_{L, i}+\sum_{j}\left(c_{P} \dot{m}_{i j} T_{i}-c_{P} \dot{m}_{j i} T_{j}\right)\right\}$

$\frac{d}{d t}\left(\rho_{i} V_{i} Y_{X, i}\right)=\dot{\Gamma}_{X, i}-\sum_{j}\left(\dot{m}_{i j} Y_{X, i}-\dot{m}_{j i} Y_{X, j}\right) \quad(X=O, F)$

The state equation of gas is given by,

$\rho T \cong 353$

In the above Eqns. (1-4), $c_{P}$ is the gas heat capacity, $\rho$ is the gas density, $T$ is the gas temperature, $T_{P}$ is the pyrolysis temperature of combustible $\nleftarrow V$ is the volume of control volume, $Y$ is the mass fraction of chemical species, $\dot{m}_{F}$ is the mass production rate of gasified fuel due to pyrolysis of combustibles, $\dot{m}$ is the mass flow rate through opening, $\dot{Q}_{B}$ is the heat release rate, $\sum \dot{Q}_{L}$ is the sum of heat loss rate through openings and walls, and $\dot{\Gamma}$ is the mass production rate of chemical species. Subscripts $i j$ and $j i$ denote the direction of mass flow between compartments $i$ and $j$. Transient change of gas temperature, density, and mass fraction of chemical species are calculated by solving these equations simultaneously.

\subsection{Mass Production Rate of Gasified Fuel}

In the event of room fire, combustibles in the room receive heat from flame and hot gas 
accumulated in the upper layer and thereby pyrolyzes to produce gasified fuel. Assuming that the mass pyrolysis rate of the combustibles is the same regardless of their positions, the mass production rate of gasified fuel $\dot{m}_{F}$ is calculated by multiplying the surface area of burning combustible $A_{F}$ and the mass pyrolysis rate per unit area $\dot{m}_{F}^{\prime \prime}$ as follows,

$\dot{m}_{F}=A_{F} \dot{m}_{F}^{\prime \prime}$

It is generally acknowledged that the mass pyrolysis rate of solid materials $\dot{m}_{F}$ can be modeled as a proportional function of the incident heat flux. However, as wooden materials, which is the most commonly used materials in dwellings, form char layers at their irradiated surfaces, it is not easy to estimate the net incident heat flux necessary to calculate the mass loss rate. Thus, we adopt the following formula derived from an experimentally obtained expression for the mass loss rate [15],

$$
\dot{m}_{F}^{\prime \prime}= \begin{cases}0.86 \dot{m}_{o}^{\prime \prime} & \left(\dot{m}_{o}^{\prime \prime} \leq 0.0082\right) \\ 0.007 & \left(0.0082<\dot{m}_{o}^{\prime \prime} \leq 0.0117\right) \\ 0.003+1.03 \dot{m}_{o}^{\prime \prime} \cdot \exp \left(-94.4 \dot{m}_{o}^{\prime \prime}\right) & \left(0.0117<\dot{m}_{o}^{\prime \prime}\right)\end{cases}
$$

where $\dot{m}_{o}^{\prime \prime}$ is the mass inflow rate of oxygen per unit surface area of the combustible.

The combustibles can be divided into following categories with regard to their modes of combustion: movable combustibles such as furniture or clothing (designated by $L$ ); and fixed combustibles such as lining or structural member (designated by $M$ ). The storage conditions of the movable combustibles can be seen in the report of an existing survey [16]. Following the 
results, exposed surface area of movable combustibles in each room $A_{F, L}$ is given as,

$A_{F, L}=0.70 w_{F, L}^{1 / 3} A_{\text {floor }}$

where $w_{F, L}$ is the mass density of movable combustibles, and $A_{\text {floor }}$ is the floor area. Whereas for the fixed combustibles, we tentatively assume that the surface area $A_{F, M}$ is identical to the internal surface are of the room $A_{T}$, that is,

$$
A_{F, M}=A_{T}
$$

However, the overall surface area of burning combustibles $A_{F}$ cannot be evaluated by just summing $A_{F, L}$ and $A_{F, M}$, since the burning area enlarges along with the development of fire. Firstly, considering that the development of fire inside of a room is often described as a time-squared model in the growth phase, we adopt a similar model for the development of burning area of the movable combustibles. Secondary, we assume that the exposed surface area of the fixed combustibles is given by a sum of the area that is initially exposed (the ratio of the initially exposed area to the internal surface area is designated as $\Psi_{0}$ ) and the area exposed after the burn-through of compartment boundaries (the ratio of the burn-through area to the internal surface area is designated as $\Psi$ ). Thus, $A_{F}$ is expressed as,

$$
A_{F}=\min \left\{\alpha_{F}\left(t-t_{i g}\right)^{2}, A_{F, L}\right\}+\min \left\{\left(\Psi_{0}-\Psi\right) A_{T}, A_{F, M}\right\}
$$

where $\alpha_{F}$ is the growth coefficient, and $t_{i g}$ is the time of ignition. 


\subsection{Heat Release Rate inside The Fire Room}

In the case of the ventilation controlled fire, the combustion in the fire room is restricted by the supply of oxygen. Assuming that the rate of chemical reaction is fast enough, heat release rate inside the fire room is governed by the mass flow rate of oxygen coming into the fire room,

$\dot{Q}_{B, O}=\Delta H_{o} \sum_{j}\left(\dot{m}_{j i} Y_{O, j}\right)$

where $\Delta H_{o}$ is the heat produced when unit mass of oxygen is consumed. While in the case of the fuel controlled fire, heat release rate inside the fire room is governed by the supply rate of gasified fuel,

$\dot{Q}_{B, F}=\Delta H_{F}\left(\dot{m}_{F}+\sum_{j} \dot{m}_{j i} Y_{F, j}\right)$

where $\Delta H_{F}$ is the heat of combustion of gasified fuel. Considering that the rate of heat release inside the fire room $\dot{Q}_{B}$ changes continuously according to the transition between the ventilation controlled fire and the fuel controlled fire, which may occur in the course of fire.

Then, $\dot{Q}_{B}$ is given by,

$\dot{Q}_{B}=\min \left\{\dot{Q}_{B, o}, \dot{Q}_{B, F}\right\}$

The rates of oxygen and gasified fuel consumed in the combustion are calculated by dividing

the heat release rate $\dot{Q}_{B}$ with their heats of combustion, respectively. Thus the mass production rate of oxygen $\dot{\Gamma}_{o}$ and that of gasified fuel $\dot{\Gamma}_{F}$ are given with the following equations, 
respectively,

$\dot{\Gamma}_{o}=-\dot{Q}_{B} / \Delta H_{o}$ and $\dot{\Gamma}_{F}=\dot{m}_{F}-\dot{Q}_{B} / \Delta H_{F}$

\subsection{Mass Transfer through Openings}

As the combustibles inside the room start to burn, pressure difference $\Delta p$ will be built between the burn room $i$ and its adjacent space $j$ which causes the mass transfer through openings between the rooms. When the neutral plane exists between the upper and the bottom edges of the opening, the mass flow rates $\dot{m}_{i j}$ and $\dot{m}_{j i}$ will be calculated with the following well known formulae, respectively,

$\dot{m}_{i j}=\frac{2}{3} \alpha B \sqrt{2 g \rho_{i} \Delta \rho}\left(H_{u}-Z_{N}\right)^{3 / 2}$ and $\dot{m}_{i j}=\frac{2}{3} \alpha B \sqrt{2 g \rho_{j} \Delta \rho}\left(Z_{N}-H_{b}\right)^{3 / 2}$

where $\alpha$ is the mass flow rate coefficient, $B$ is the width of the opening, $g$ is the acceleration due to gravity, $\Delta \rho$ is the density difference, $H_{u}$ is the upper edge height of the opening, $H_{b}$ is the bottom edge height of the opening, and $Z_{N}$ is the height of the neutral plane. Yet, as the pressure profile at opening changes significantly with the development of thermal conditions in the facing spaces, we need to assume different pressure profiles. Thus, all of the mass flow rate equations of possible pressure profiles are provided in the model besides of the Eqn.(14).

The height of the neutral plane $Z_{N}$ is the height at which the pressure difference between 
two contiguous spaces becomes zero. In obtaining $Z_{N}$, hydrostatic pressure gradient is assumed for the pressure inside a room, that is,

$p(z)=p_{0}-\rho g z+C_{W} \cdot \frac{1}{2} \rho U_{\infty}^{2}$

where $p_{0}$ is relative pressure of the space to the atmospheric pressure at the ground level, $C_{W}$ is the wind pressure coefficient, and $U_{\infty}$ is the wind speed. The third term in the right hand side of the Eqn. (15) represents the wind pressure, which becomes zero when the concerning opening is not on the exterior wall. The wind pressure coefficient $C_{W}$ is expressed as a function of the attack angle of the wind into the wall, $\theta$, as follows based on the existing wind tunnel experiment [17],

$C_{W}= \begin{cases}0.75 & (-1 \leq \cos \theta \leq-0.866) \\ -0.45-1.38 \cos \theta & (-0.866 \leq \cos \theta \leq 0) \\ -0.45 & (0 \leq \cos \theta \leq 1)\end{cases}$

As the relative pressure $p_{0}$ in Eqn. (15) cannot be described explicitly, it is evaluated by implicitly solving the mass conservation equation of the compartment gas. However, as there are mass conservation equations as many as the number of rooms in the building and the mass conservation equations are coupled each other, the problem is reduced to be the solution of a system of nonlinear simultaneous equations. In the current study, Newton method is adopted in solving this problem.

\subsection{Heat Transfer through Openings and Walls}


Elevation of temperature inside the fire room brings the transfer of abundant heat to the neighboring rooms, and even the ignition of combustibles when it is intense. There are two modes of heat transfer through openings, that is, one by vent flow of hot gases and other by thermal radiation. On the latter, assuming that the gas is black, the rate of net heat transfer from a space $i$ to the adjacent space $j$ is given by,

$\dot{Q}_{D, j j}=\left\{\sigma\left(T_{i}^{4}-T_{j}^{4}\right)+\dot{q}_{R}^{\prime \prime}\right\} A_{D}$

where $\dot{q}_{R}^{\prime \prime}$ is the radiant heat flux transferred from the neighboring buildings involved in fire, and $A_{D}$ is the area of the opening. Notice that $\dot{q}_{R}^{\prime \prime}$ becomes zero when the concerning opening is not on an exterior wall so is not exposed to the external heating.

As to the compartment boundaries such as walls and doors, thermal radiation heat transfer and convective heat transfer are considered as the mechanisms of heat transfer. Thus, the rate of net heat loss from the compartment gas in room $i$ to the boundary separating the neighboring spaces $i$ and $j$ is given as,

$\dot{Q}_{M, i j}=\left\{\varepsilon_{M} \sigma\left(T_{i}^{4}-T_{M, i}^{4}\right)+h_{M}\left(T_{i}-T_{M, i}\right)+\dot{q}_{R}^{\prime \prime}\right\} A_{M}$

where $\varepsilon_{M}$ is the emissivity of the boundary surface, $h_{M}$ is the convective heat transfer coefficient, $T_{M, i}$ is the surface temperature of the boundary, and $A_{M}$ is the surface area of the boundary. As the thickness of walls or doors are small compared to the lengths of surfaces in 
general, the surface temperature $T_{M, i}$ necessary for the calculation of $\dot{Q}_{M, i j}$ is obtained by solving one dimensional heat conduction equation numerically.

\subsection{Burn-through of Compartment Boundary and New Opening}

When walls and doors are exposed to severe heating for a certain period, component materials start to degrade and even collapse. Such deficit of the compartment boundary allows the spilling of hot gas and brings dramatic increase in the radiation heat transfer to the adjacent room. Thus the adequate prediction of the burn-through is crucial for the fire spread prediction. Although the mechanism of burn-through is intrinsically complex, we now assume that it initiates when the accumulation of the incident heat flux exceeds a critical value $Q_{c r}^{\prime \prime}$. Then the time at which the burn-through initiates $t$ takes the form,

$\int_{0}^{t} \dot{q}_{M}^{\prime \prime} d t>Q_{c r}^{\prime \prime}$

where $\dot{q}_{M}^{\prime \prime}$ is the incident heat flux. The model in Eqn.(19) describes the fire resistance

performance of boundary material in terms of the magnitude of $Q_{c r}^{\prime \prime}$. However, $Q_{c r}^{\prime \prime}$ is not a

pertinent index from the viewpoint of generality, as it is not a value that can be obtained through the implementation of widely available test methods. Thus, we transform $Q_{c r}^{\prime \prime}$ into an alternative index, critical time $t_{c r}$, so to call the burn-through time,

$$
Q_{c r}^{\prime \prime}=\int_{0}^{t c r} \dot{q}_{\text {standard }}^{\prime \prime} d t
$$


where $\dot{q}_{\text {standard }}^{\prime \prime}$ is the incident heat flux under the heating of the standard fire curve ISO834,

which is widely accepted in the fire resistance test method of building structures. In other words, a wall with burn-through time $t_{c r}$ has a fire resistance property equivalent to that of a wall that endures the standard fire test until the time $t_{c r}$ without causing any burn-through.

On estimating the dimension of deficit on the compartment boundary, the rate of burn-through enlargement is assumed to be proportional to the incident heat flux $\dot{q}_{M}^{\prime \prime}$, which is an analogy to the evaporation of liquids or the pyrolysis of solid materials. Thus the decrease rate of material density in the burn-through process is given as,

$$
\Delta_{M} \frac{d \rho_{M}}{d t}=\frac{\dot{q}_{M}^{\prime \prime}}{L_{M}}
$$

where $\Delta_{M}$ is the thickness of the compartment boundary, and $L_{M}$ is the proportionality

constant that determines the rate, so to call the latent heat of burn-through. The resulting density change makes a deficit upon the boundary perpendicular to the plane surface. We now name the proportion of the deficit area to the overall wall surface area as deficit fraction $\Psi$, which is identical to the parameter used in evaluating the burning area of fixed combustibles in Eqn. (9). Assuming that the deficit fraction $\Psi$ is proportional to the material density,

$$
\Psi=\frac{\rho_{M, 0}-\rho_{M}}{\rho_{M, 0}}
$$

where $\rho_{M, 0}$ is the initial density of the boundary material. With the deficit fraction $\Psi$, area of 
newly formed opening is given by,

$$
A_{D}=\Psi \cdot A_{M}
$$

The deficit originates at the geometrical center of the boundary, and enlarges its area $A_{D}$ towards the horizontal and vertical direction at an identical rate of $d D / d t$ as shown in Fig. 2.

\section{BUILDING-TO-BUILDING FIRE SPREAD MODEL}

\subsection{Thermal Radiation Heat Transfer from Fire Involved Buildings}

Thermal radiation is one of the most important factors which cause fire spread. However, the extent of its impact is restricted within the buildings relatively close to the building on fire, as radiation from the heat source is shielded by other buildings in a densely built urban area. In the model, hot gas inside the fire room and flame vented from an opening are the two radiation heat sources against the neighboring buildings.

As to the room gas, radiation heat flux transferred from a heat source surface $j$ to another surface of a component structure of the target building $i$ is expressed as,

$\dot{q}_{R}^{\prime \prime}=\varepsilon \sigma T_{j}^{4} F_{i j}$

where $\varepsilon$ is the surface emissivity, $T$ is the gas temperature obtained from the governing Eqns. (1-4), $\sigma$ is the Stefan-Boltzmann constant, and $F_{i j}$ is the view factor. The view factor 
$F_{i j}$ is calculated by solving the following equation of definition numerically,

$A_{i} F_{i j}=A_{j} F_{j i}=\iint_{A_{i} A_{j}} \frac{\cos \beta_{i} \cos \beta_{j}}{\pi s^{2}} d A_{j} d A_{i}$

where $A$ is the area, $\pi$ is the circumference ratio, $s$ is the length of the line between

element cells, and $\beta$ is the angle between the normal vector of the plane and the line. The

effect of shielding by neighboring buildings is also considered.

Schematic diagram of the heat transfer from the window flames is illustrated in Fig.3.

Although the temperature of the window flame varies within its spatial extent, its radiation properties are represented by a point source $\mathbf{X}$ for the ease of computation. If the overall heat flux that passes a sphere of any radius is identical to the total radiation energy from the point source, then the radiant heat flux transferred to a building component at the distance of $s$ from the point $\mathbf{X}$ will be,

$\dot{q}_{R}^{\prime \prime}=\varepsilon\left(\frac{\chi_{R} \dot{Q} \cos \theta}{4 \pi s^{2}}\right)$

where $\dot{Q}$ is the apparent heat release rate of the window flame, $\chi_{R}$ is the fraction of radiant heat loss to the total heat release, and $\theta$ is the angle between the target wall and the line drawn from the representative point, $\mathbf{X}$, to the gravity point of the target wall. The apparent heat release rate, $\dot{Q}$, is evaluated as the sum of the rate of heat discharged by convection from the fire compartment, and the rate of heat released of excess gasified fuel burnt outside of the 
compartment, that is,

$\dot{Q}=\dot{m} \cdot c_{P}\left(T-T_{\infty}\right)+\dot{m} \cdot \Delta H_{F} Y_{F}$

The effect of radiation shielding by neighboring buildings is not considered directly for the

window flame. However, whether the concerning wall is shielded from the window flame or not is indirectly determined from the calculation results of wall-to-wall view factors. That is, if the wall-A is shielded from another wall-B, then the flame window from the wall-A is also deemed to be shielded from wall-B.

Referring to Fig.3, position of the representing point $\mathbf{X}$ relative to the reference point $\mathbf{O}$ at the upper end of the window is expressed as follows,

$\overrightarrow{O X}=D_{f l} \mathbf{e}_{x}+\frac{L_{f l}}{2} \mathbf{e}_{z}$

where $D_{f}$ is the distance between the wall surface and the flame trajectory, $\mathbf{e}_{x}$ is the unit

vector normal to the wall, and $\mathbf{e}_{z}$ is the unit vector directed vertically upward. The distance

$D_{f l}$ is calculated with the following equation deduced from the model experiment [18],

$\frac{D_{f l}}{B}=0.21 F^{*}$

where $F^{*}$ is the dimensionless parameter defined as a function of maximum horizontal flow

velocity at the opening $u_{0}$, and the apparent heat release rate $\dot{Q}$, as follow, 
$F^{*} \equiv\left(\frac{u_{0}}{\sqrt{g B}}\right)^{2}\left(\frac{\dot{Q}}{\rho_{\infty} c_{P} T_{\infty} g^{1 / 2} B\left(H-Z_{N}\right)^{3 / 2}}\right)^{-2 / 3}$

in which $T_{\infty}$ is the ambient temperature, and $\rho_{\infty}$ is the ambient density. Equations $(29,30)$

shows that the distance $D_{f}$ gets larger when either the horizontal velocity $u_{0}$ gets larger or the apparent heat release rate, $\dot{Q}$, gets smaller. On the other hand, the flame height $L_{f l}$ is assumed as the height of the boundary between the intermittent flame region and the plume region derived in the previous report [19] as follows,

$\frac{L_{f}}{H-Z_{N}}=2.44$

The relation in Eqn.(31) appears that the height of the window flame $L_{f l}$ is independent of the heat release rate $\dot{Q}$. However, as Eqn.(31) involves the height from the neutral plane to the upper edge of the opening $H-Z_{N}$ the flame height $L_{f}$ in Eqn.(31) implicitly represents the effect of the heat release rate $\dot{Q}$.

\subsection{Temperature Rise due to The Wind-blown Fire Plumes}

When a plume originated from a fire is blown down by wind, extensive area in the downwind will be enveloped in the plume (Fig.4). In fact, as the air flow over the urban area is turbulent by nature, behavior of a fire plume is expected to be complex. However, as there is not much information available on the modeling of such behavior at this moment, we assume that the wind effect on the diffusion characteristic of the plume is negligible and that the temperature 
rise along the trajectory $\Delta T_{m}$ is about the same as that of the point heat source in a quiescent atmosphere,

$\Delta T_{m}=24\left(\frac{\xi}{\dot{Q}^{2 / 5}}\right)^{-5 / 3}$

where $\xi$ is the distance along the plume trajectory from the geometrical center of the relevant opening. Radial temperature distribution from a trajectory line is assumed to take normal distribution, that is the temperature rise at a radial distance $r$ away from the trajectory line is described as follows,

$$
\frac{\Delta T(r)}{\Delta T_{m}}=\exp \left[-\left(\frac{r}{b_{T}}\right)^{2}\right]
$$

where $b_{T}(\cong 0.1 \xi)[20]$ is the half-width of the temperature rise. Wind is assumed to be strong enough, so that the wind velocity profile is not affected by the fire plume.

As is apparent from Fig.4, $r$ is the minimum distance from the trajectory to the target compartment. In order to evaluate $r$, the inclined angle $\theta$ of the fire plume is needed. The inclined angle $\theta$ is given by the following formula derived by Yokoi from the existing line heat source experiment [21],

$\tan \theta=0.1 \Omega^{-3 / 4}$

where $\Omega$ is the dimensionless parameter defined as follows, 
$\Omega \equiv \frac{U_{\infty}}{\left(\frac{\dot{Q}^{\prime} g}{c_{P} \rho_{\infty} T_{\infty}}\right)^{1 / 3}}$

where $U_{\infty}$ is the wind velocity, $\dot{Q}^{\prime}$ is the heat release rate per unit length, which is calculated as $\dot{Q}^{\prime}=\dot{Q} / \sqrt{A_{\text {floor }}}$ in the computation, where $A_{\text {floor }}$ is the floor area.

Now, as an urban fire is an ensemble of multiple building fires, a specific building in an urban area may possibly be under the overlapping effect of multiple fire plumes originated somewhere in the upwind. Assuming that the thermal properties of individual fire plumes are independent from the other fire plumes, following overlapping relation is adopted for the estimation of the overall elevation of ambient temperature around the concerning building [22],

$\Delta T=\left(\sum_{i=1}^{N} \Delta T_{i}^{3 / 2}\right)^{2 / 3}$

where the subscript $i$ indicates the identifying symbol of the fire plume, and $N$ is the total number of concerning fire plumes.

\subsection{Firebrand Spotting}

Enormous number of firebrands is released into the fire-induced flow field in case of an urban fire. However, as the occurrence of ignition by a firebrand depends on the properties of the firebrand, properties of target combustible, local-scale wind conditions, atmospheric conditions, etc., only a fraction of the released firebrands actually causes the fire spread. As reflecting all of these conditions on the brand spotting model is virtually impossible, we employ a probabilistic 
approach. Then the occurrence of the fire spread caused by the $i$-th firebrand at a building whose relative spatial coordinate to the fire building is $(X, Y)$, is a stochastic phenomenon consisting of the following events to be occurred sequentially: (1) the firebrand is transported to the location $(X, Y) ;(2)$ there is a combustible on which the firebrand lands; and (3) the firebrand ignites the combustible. However, as we have insufficient knowledge as to the events (2) and (3), we are not able to develop appropriate prediction method. So in the current model, we assumed the probabilities of these events as constants, and express the probability of occurrence of the building to building fire spread by firebrand $p_{s, i}$ as follows,

$p_{S, i}=\alpha_{B} \cdot p_{B, i} \quad(i=1 \sim N)$

where $\alpha_{B}$ is the constant, and $p_{B, i}$ is the probability of the event (1) to be occurred.

The probability of firebrand distribution $p_{B, i}$ is described incorporating the results of the numerical simulation on the transport behaviors of disk-shaped firebrands [23]. Specifying the concerning fire involved building to be the coordinate origin $O^{\prime}$, we approximate the scattering probability along the wind direction (that is, $X$-axis) with a log-normal distribution $p_{B, X}$ and that of the orthogonal direction (that is, $Y$-axis) with a normal distribution $p_{B, Y}$. Then the overall distribution is given by a product of $p_{B, X}$ and $p_{B, Y}$, which is, $p_{B}=p_{B, X} \cdot p_{B, Y}$ 


$$
\left\{\begin{array}{l}
p_{B, X}=\frac{1}{\sqrt{2 \pi} \sigma_{L, X} X} \exp \left\{-\frac{\left(\ln X-\mu_{L, X}\right)^{2}}{2 \sigma_{L, X}^{2}}\right\} \quad(0<X<\infty) \\
p_{B, Y}=\frac{1}{\sqrt{2 \pi} \sigma_{Y}} \exp \left(-\frac{Y^{2}}{2 \sigma_{Y}^{2}}\right) \quad(-\infty<Y<\infty)
\end{array}\right.
$$

where $\mu_{L, X}$ and $\sigma_{L, X}$ are the mean and standard deviation of logarithm natural of the transport distance $\ln X$, respectively. Whereas for the $Y$-direction, the mean transport distance is set to be 0 , and only the standard deviation $\sigma_{Y}$ is considered. As an urban fire is an ensemble of multiple building fires, the above prediction process can be applied to individual buildings in an urban area, which is similar to the prediction process of temperature rise due to wind blown fire plumes. However, in contrast to the case of fire plumes, ignition probability of a specific building by firebrands can be predicted by just taking a sum of ignition probabilities for all of the corresponding fire involved buildings in the upwind. This is because the scattering distribution of firebrands released from a fire involved building is independent from the ones of other fire involved buildings.

We can evaluate the scattering distribution of firebrands by substituting $\mu_{L, X}, \sigma_{L, X}$ and $\sigma_{Y}$ in the above Eqn.(38) with specific values, which is also given in the existing literature as [23],

$$
\left.\left.\begin{array}{l}
\mu_{X} / D=0.47 B^{* 2 / 3} \\
\sigma_{X} / D=0.88 B^{* / 3}
\end{array}\right\} \text { and } \begin{array}{l}
\mu_{Y} / D=0 \\
\sigma_{Y} / D=0.92
\end{array}\right\}
$$

Note that $\mu_{X}$ and $\sigma_{X}$ need to be converted into the form of logarithm natural, that is $\mu_{L, X}$ and $\sigma_{L, X}$, before substituting into Eqn.(38). The dimensionless parameter $B^{*}$, which governs 
the transport behaviors of firebrands, is a combined function of the dimensionless wind speed $U_{\infty} / \sqrt{g D}$, dimensionless density $\rho_{P} / \rho_{\infty}$, dimensionless length $d_{P} / D$, and dimensionless heat release rate $\dot{Q} /\left(\rho_{\infty} c_{P} T_{\infty} g^{1 / 2} D^{5 / 2}\right)$, that is,

$B^{*} \equiv \frac{U_{\infty}}{(g D)^{1 / 2}}\left(\frac{\rho_{P} d_{P}}{\rho_{\infty} D}\right)^{-3 / 4}\left(\frac{\dot{Q}}{\rho_{\infty} c_{P} T_{\infty} g^{1 / 2} D^{5 / 2}}\right)^{1 / 2}$

where $D$ is the length scale of the fire origin, which is calculated as a square root of the floor

area $\sqrt{A_{\text {floor }}}, \rho_{P}$ is the firebrand density, and $d_{P}$ is the width of the square shaped firebrand.

With the above expressions, the scattering of an individual firebrand can be tracked. Now, the release conditions of these firebrands need to be considered in addition. In the existing full scale experiment, it is reported that the release of firebrands increased dramatically after the occurrence of flashover inside the fire compartment [24]. Taking into account of this finding, number of released firebrands $N_{B}$ is expressed as a function of a cumulative heat release after the flashover as follows,

$$
N_{B}=\beta_{B} \cdot \int_{t_{F O}}^{t} \dot{Q}_{B} d t
$$

where $\beta_{B}$ is the constant, and $t_{F O}$ is the flashover time. Although there is not an universally agreed definition of flashover, we assume that it is occurred when the enlarging burning area $A_{F}$, reaches the overall surface area of movable combustible $A_{F, L}$. 


\section{FIRE SPREAD SIMULATION IN A HYPOTHETICAL URBAN AREA}

As a model verification, a number of fire spread simulations were carried out in a

hypothetical urban area in order to quantify contributions of the fire spread phenomena, window

flame, fire plume, and firebrand spotting. The obtained fire spread rates were compared with the predictions of the Hamada model, which has been widely used in practice at the moment. In the Hamada model, fire spread rates toward the downwind direction and the orthogonal direction are given as follows, respectively $[4,5]$,

(downwind direction) $V=\frac{\left(a^{\prime}+b^{\prime}\right)\left(1-c^{\prime}\right)}{a^{\prime}+5 b^{\prime} / 3} \frac{(a+d)\left(1+0.1 U_{\infty}+0.007 U_{\infty}^{2}\right)}{3+3 a / 8+8 d / 1.15 \beta\left(5+0.5 U_{\infty}\right)} \quad(\mathrm{m} / \mathrm{min})$

(orthogonal direction) $V=\frac{\left(a^{\prime}+b^{\prime}\right)\left(1-c^{\prime}\right)}{a^{\prime}+5 b^{\prime} / 3} \frac{(a+d)\left(1+0.002 U_{\infty}^{2}\right)}{3+3 a / 8+8 d / 1.15\left(5+0.2 U_{\infty}\right)}(\mathrm{m} / \mathrm{min})$

where $a$ is the average side length of buildings, $d$ is the average separation of buildings, $a^{\prime}$ is the ratio of wooden buildings with bare structural materials (building type A), $b^{\prime}$ is the ratio of wooden buildings with mortar plastered structural materials (building type B), $c^{\prime}$ is the ratio of fire resistant buildings (building type $\mathrm{C}$ ), and $\beta$ is the model parameter deduced from the record of the past urban fires. Note that as buildings are assumed to have square plans in the Hamada model, the parameters $a$ and $d$ are generally obtained by taking average values in a certain spatial range. As a consequence, irregular configurations of buildings in real urban areas need to be smoothed out in the Hamada model.

\subsection{Calculation Conditions}


Calculation conditions assumed in the subsequent simulations are shown in Table 1. In the hypothetical urban area, 2,500 two-story buildings (lines of 100 buildings along the wind direction and 25 buildings along the orthogonal direction) were aligned on a grid with an even separation of $4 \mathrm{~m}$. Configurations of the buildings were identical, which has a square shape floor of $8 \mathrm{~m}$ by $8 \mathrm{~m}$, and story height of $3 \mathrm{~m}$. The control volume for the simulation of an individual building fire was set to be the occupational space of each floor. The assumed elevation of the building and the spacing between adjacent buildings are illustrated in Fig.6, in which the ratio of the opening area to the wall was set to be 0.3 according to the existing field survey [14].

Three building types of different fire resistant properties, that is, the wooden building (building type A), the mortar plastered wooden building (building type B), and the fire resistant building (building type C) as referred in the Hamada model, were assumed in the numerical simulation. The fraction of each building type is shown in Table 1. Types of the buildings were chosen randomly according to these fractions beforehand of the calculation. The assumed properties related to burning of each building type are shown in Table 2. However, the initially exposed surface area of fixed combustibles were adjusted, so as the fire spread rate to the downwind direction agrees well with the result of Hamada model at the wind velocity of $2.5 \mathrm{~m} / \mathrm{s}$.

The fire was started at the ground floor of the building in the 26th line of the wind direction, 13th line of the orthogonal direction. Reference wind velocity $U_{\infty}$ was varied from $2.5,5.0$, to 
$10.0 \mathrm{~m} / \mathrm{s}$, in which no fluctuation was considered. The rest of the physical parameters related to

fire spread are shown in Table 3. These include a parameter which describes the probability of fire spread due to firebrand spotting $\alpha_{B} \beta_{B}$. As is evident, this is a combined parameter of $\alpha_{B}$ in Eqn.(37), and $\beta_{B}$ in Eqn.(41). The parameter $\alpha_{B} \beta_{B}$ was varied from 0.0, $1.0 \emptyset 10^{-6}$, to 2.0 $\varnothing 10^{-6}$. So the total number of the numerical conditions was 9 , which is the combination of 3 different conditions for the wind velocity $U_{\infty}$, and 3 different conditions for firebrand spotting.

\subsection{Results and Discussion}

Examples of the simulated fire spread are shown in Fig.7 in a sequence of time, where burnt-out buildings are colored with dark grey and on-burning buildings with red. The ones in the column (A) show the results at $U_{\infty}=5.0 \mathrm{~m} / \mathrm{s}$, and the ones in the column (B) shows the results at $U_{\infty}=10.0 \mathrm{~m} / \mathrm{s}$. Note that the parameter on the firebrand spotting, $\alpha_{B} \beta_{B}$, was set to be $1.0 \emptyset 10^{-6} \mathrm{~kJ}^{-1}$ in the corresponding results.

The fire spread from the fire origin to every direction, and the spread rate to the downwind was the largest among those to the entire direction. There are two conceivable causes: one is because hot plumes originated from fire buildings were blown down by the wind and raised the ambient temperature in the downwind region; another is because firebrands released from the fire involved buildings were mostly scattered in the downwind and caused the spot ignition. While, the reason for the asymmetrical fire spread with respect to the wind direction is due to 
the random alignment of buildings of different burning properties, as well as the probabilistic prediction process of the fire spread by firebrands. When a certain time passed after the outbreak, the fire started to decay at buildings near the fire origin, and a line-shape burning area was formed at the fire front. The width of this fire front was largest in the downwind, where fire spread rate was the largest.

As an urban area of simple configuration was assumed in the current calculation, there was not much qualitative difference in the results of the presented model and the Hamada model in general. However, there was a difference in fire spread in the orthogonal direction, that is, the Hamada model in Eqns. (42) and (43) predicted fire spread rate to be the largest in the line of the fire origin which is the 26th line, while the presented model predicted the fire spread rate to be the largest in slightly leeward positions.

Relationships between the time and spread distance are shown in Figs.8, 9, and 10, where solid lines and dotted lines are the results of the Hamada model and the present model, respectively. However, as we adopted a probabilistic model for the firebrand scattering and the model does not provide a unique result even though the numerical conditions are the same, Monte-Carlo Simulations with 500 trials for each numerical conditions were carried out in order to obtain the expectations of the fire spread distance.

As the ratio of initially exposed surface area to overall surface area, $\Psi_{0}$ was adjusted, the 
predicted fire spread distance at the wind velocity $U_{\infty}$ of $2.5 \mathrm{~m} / \mathrm{s}$ agreed well with that of the

Hamada model. However, as the wind velocity was small, there was no apparent difference in the spread distance regardless the change in the parameter $\alpha_{B} \beta_{B}$. Whereas, when the wind velocity $U_{\infty}$ increases, the effect of the parameter $\alpha_{B} \beta_{B}$ became dominant as shown in Figs.9 and 10. We obtained the larger the parameter $\alpha_{B} \beta_{B}$, the larger the spread distance. The results of the two models agreed best at $\alpha_{B} \beta_{B}=0.0 \mathrm{~kJ}^{-1}$ when $U_{\infty}=5.0 \mathrm{~m} / \mathrm{s}$, and $\alpha_{B} \beta_{B}=1.0 \emptyset 10^{-6} \mathrm{~kJ}^{-1}$ when $U_{\infty}=10.0 \mathrm{~m} / \mathrm{s}$.

We have seen that the fire spread faster to the downwind direction with the increase of the wind velocity $U_{\infty}$. On the contrary, there was no apparent effect of wind velocity $U_{\infty}$ on the spread rate to the upwind direction. As a result, the present model underestimated the corresponding value compared to that of the Hamada model. Thus, the discrepancy became more significant when the wind velocity $U_{\infty}$ was larger. Incidentally, there was no effect of the parameter $\alpha_{B} \beta_{B}$ on the fire spread to the upwind direction, as no firebrand is expected to be transported to the upwind in the model.

\section{FIRE SPREAD SIMULATION OF THE SAKATA FIRE}

Fire spread simulation of the 1976 Sakata Fire was carried out for the additional model verification. A devastating fire occurred in a northern city of Japan called Sakata in a windy day 
of October 1976. The fire originated from a movie theater in the middle of downtown and propagated to the adjacent buildings sequentially. In spite of the considerable effort made by fire fighters, the fire enlarged its area and lasted for about 11 hours after outbreak. As a result, as many as 1,774 buildings and site area of 22.5 ha were burnt. Outline of the fire is depicted in Table 4 [25].

The bird's eye view and aerial photograph of the burnt area are shown in Figs. 11 and 12. In each figure, the overall burnt area is surrounded by dotted line. The predominant direction of fire spread was ESE from the fire origin, which was roughly the same as the wind direction throughout the fire. The fire finally reached as far as the Niidagawa-river (about 50m wide) about $800 \mathrm{~m}$ away from the fire origin. Although there was a fairy broad street called Hamamachi-dori (about $15 \mathrm{~m}$ wide) on the way, the momentum of the fire was overwhelming that it did not work well as a fire-break.

The weather data recorded at the meteorological station about $1 \mathrm{~km}$ away from the fire origin is shown in Fig.13. Even though the Sakata area is well known for its frequent strong wind, the day of the fire was especially windy that the average wind velocity $11.0 \mathrm{~m} / \mathrm{s}$. While the fire, intermittent rainfall was also observed. However, as the maximum precipitation rate was $2 \mathrm{~mm} /$ hour and the overall precipitation amount was $12 \mathrm{~mm}$ throughout the fire, its contribution to fire suppression was supposed to be limited. 
The number of assembled fire engines/pumps was 217 , and that of available fire

hydrants/tanks was about 50 excluding direct water supply from Niidagawa-river. In spite of such abundant resources for fire fighting, momentum of the fire was prevailing and was unextinguishable before it reached Niidagawa-river. This is because the growth of the fire was rapid that extinguishment of the fire at the initial phase was failed.

\subsection{Calculation Conditions}

Data on building configuration, number of stories, construction types needed for the numerical simulation were all scanned from the city planning map of that time drawn in the scale of 1/1000. Inequalities of the ground level are not considered in the current simulation. The number of scanned buildings was 2,158 , whereas the number of recorded burnt buildings was 1,774 . The control volume for the simulation of an individual building fire was set to the occupational space of a floor. Wind and ambient temperature data obtained at the meteorological station were used as the input weather data as shown in Fig.13. However, fire suppression effect of neither rainfall nor fire fighting was considered in the present simulation. Following the previous simulation in the hypothetical urban area, buildings were categorized into 3 structural types: wooden buildings with bare structural materials (building type A); wooden buildings with mortar plastered structural materials (building type B); and fire resistant buildings (building type C) as shown in Table 2. 
Other model parameters assumed in the simulation of the Sakata Fire were shown in Table 3 except for the ones of firebrand spotting. Enormous amount of lofted firebrands were observed and numbers of fire spreads were actually caused by them. The present model is capable of predicting fire spread caused by firebrands. However, as the model takes probabilistic approach for the spotting simulation, obtained results may become different for every trial of simulation even if the input data are unchanged. One way of evaluating such results is to duplicate simulation by the Monte-Carlo approach and deduce expected behaviors of fire spread. Yet, the observed fire behavior itself is only an example of considerable number of expected fire scenarios. Thus, the observed time and place, at which secondary fires caused by firebrands, were used as input data instead of predicting them.

\subsection{Results and Discussion}

Simulated fire spread at 22:00 (Oct. 29th), 0:00 (Oct. 30th), and 2:00 (Oct. 30th) were visualized in Figs. 14, 15, and 16, respectively. Burnt-out buildings are colored with dark grey and on-burning buildings with red. Buildings of the secondary fire origin initiated by firebrands and their corresponding times are indicated with arrows. Once initiated, the fire quickly propagated to adjacent buildings one after another and extended the burn area. In contrast to the previous simulation in the hypothetical urban area, there was less regularity in locations and configurations of buildings in the city of Sakata. However, the predominant fire spread direction 
was still identical to the wind direction, which implies behaviors of wind-blown fire plume and firebrand spotting are influential on the fire spread dynamics of urban fires.

Dynamics of fire spread in the fire record and simulated result are illustrated in Fig.17. The fire origin and secondary fire origins are designated with the symbols $(\circ)$ and $(\bullet)$, respectively. Curved lines show positions of fire front at the indicated times. Qualitative features of fire spread are similar between the fire record and the numerical result, i.e.: the coincidence of the predominant fire spread direction and the wind direction; and the rate of fire spread estimated from the intervals of the fire fronts.

However, there are two areas where fire front intervals are notably short in Fig.17(B), which indicate underestimation of fire spread rate. They are around the cross-point of Takumimachi-Ginza St. and Shimonoyama St., and the cross-point of Nakamachi St. and Hamamachi St. As obvious from the three dimensional view of the city in Figs. 14, 15, or 16, there are fairly large open spaces around the concerning area including those of the streets. In the present simulation, buildings scanned from the city map were regarded as the only combustibles in the urban area. Whereas in actual fires, there is usually a variety of intervening combustibles, such as vegetations, warehouses or even vehicles, which probably enhance momentum of fire spread. This specific case was not an exception. Additionally, it is natural to assume that the recorded secondary fire origins caused by firebrands are only a part of those 
actually caused as it is hard to distinguish contributing factors of fire spread in the disorder of such an extraordinary fire. Another possible reason is the lack of accuracy in the prediction of building-to-building fire spread. Although the occurrence of fire spread is judged by comparing either of the incident heat flux through opening or the surface temperature of exterior wooden wall with their critical values, hysteresis effect of heating is not considered in the present model. This becomes influential on the ignition of material when intensity of the heat is small, i.e., when separation of buildings is large.

On the other hand, the overall burnt area was overestimated in the simulation as the suppression effect of fire fighting activity was neglected in the present model (see Fig.17). While in the fire, considerable efforts were made by residents, fire fighters and even self-defense force. Total number of fire engines/pumps operated in the incident was as many as 217 , including the ones from the neighboring cities of Sakata. The overestimation is remarkable especially in the orthogonal directions of the wind. It is reported that there were a substantial temperature rise and smoke dispersion in the area downstream of the fire involved buildings due to the exposure to wind-blown fire plumes. This made the implementation of fire fighting activity difficult in the concerning area, and as a result, the actual water discharge was restricted mainly from the orthogonal direction of the wind. The stoppage of the fire in this direction clearly shows the effect of fire fighting. 


\section{CONCLUSIONS}

In this paper, a computational model for urban fire spread was developed in order to be used for evaluation of fire spread risk in densely-built urban areas. Present model is distinct from the previous models in that it is based upon physics-based understandings of fire behaviors, and thus, the model describes clear cause-and-effect relationship in fire spread dynamics. As a result, the model is capable of evaluating hazard of fire spread in a quantitative and rational manner which is appropriate for countermeasure design of urban fires.

In the model, fire spread in urban area is described as an ensemble of multiple building fires, that is, the fire spread is simulated by predicting behaviors of individual building fires under the thermal influence of neighboring building fires. Adopted numerical technique for the prediction of individual building fire is based on the one-layer zone model, and a compartment inside building is assumed as a control volume. As for the building-to-building fire spread, three phenomena are considered as contributing factors: (I) thermal radiation from fire involved buildings; (II) temperature rise due to wind-blown fire plumes; and (III) firebrand spotting.

As for the model verification, fire spread simulations were carried out in a hypothetical urban area, where 2,500 buildings of identical configurations were aligned at an even separation. The calculated fire spread rates were then compared with that of the Hamada-model, and reasonable 
agreements were obtained by adjusting the model parameter $\alpha_{B} \beta_{B}$. However, no apparent effect of wind velocity on the fire spread rate to the upwind direction was observed, and the spread rate was underestimated compared to that of the Hamada model.

Simulation of a well known urban conflagration which took place in the city of Sakata in 1976 was carried out for the additional verification. Qualitative features of the fire spread obtained in the simulation, such as the predominant fire spread direction or the overall rate of fire spread, showed reasonable agreements with the fire record. However, there were several discrepancies, i.e., the underestimation of fire spread rate where buildings were scarcely sited, and to the contrary, the overestimation of fire spread area in the orthogonal direction of the wind. Major reasons presumed for these discrepancies are as follow: (1) buildings specified in the city planning map were regarded as the only combustibles and intervening elements of fire spread such as vegetations, warehouses, vehicles were disregarded; (2) only a part of secondary fire origins caused by firebrands were considered as the input data. (3) hysteresis effect of heating on the material ignition was not considered; and (4) suppression effect of the fire fighting and rainfall were not incorporated.

Present paper describes a basic framework of urban fire spread modeling. The model has capability of further development, for example by incorporating new sub-models: (1) a fire suppression model for evaluating effectiveness of fire fighting activity; (2) a bush fire model for 
simulation of urban/wildland interface fire; (3) a model for evaluating structural damage of buildings which may be caused by shaking of earthquake. Development of convenient user interface which enables countermeasure design for city planners, consultants, or fire fighters is another possibility of progress.

\section{NOMENCLATURE}

\section{Alphabets}

A Surface area $\left(\mathrm{m}^{2}\right)$

$B \quad$ Width of opening (m)

$B^{*}$ Dimensionless number defined in Eqn.(40) (-)

$b_{T} \quad$ Half-width of plume with regard to temperature rise (m)

$C_{W}$ Wind pressure coefficient (-)

$c_{P} \quad$ Heat capacity of gas $(\mathrm{kJ} / \mathrm{kgK})$

$D$ Representative scale of heat source (m)

$D_{f l}$ Shortest distance between window flame and exterior wall (m)

$d \quad$ Width (m)

$F \quad$ View factor (-)

$F^{*}$ Dimensionless number defined in Eqn.(30) (-)

$g$ Acceleration due to gravity $\left(\mathrm{m} / \mathrm{s}^{2}\right)$ 
$H \quad$ Height of opening (m)

$\Delta H$ Heat of combustion $(\mathrm{kJ} / \mathrm{kg})$

$L_{f l} \quad$ Height of window flame (m)

$L_{M}$ Heat of burn-through $(\mathrm{kJ} / \mathrm{kg})$

$\dot{m}$ Mass flow rate $(\mathrm{kg} / \mathrm{s})$

$\dot{m}_{F}$ Mass loss rate of combustible $(\mathrm{kg} / \mathrm{s})$

$\dot{m}_{o}$ Mass supply rate of oxygen $(\mathrm{kg} / \mathrm{s})$

$N_{B}$ Number of firebrands released from a fire involved building (-)

$p \quad$ Probability (-)

$p_{0}$ Reference pressure at the ground level $(\mathrm{Pa})$

$\Delta p$ Pressure difference $(\mathrm{Pa})$

$\dot{Q} \quad$ Apparent heat release rate of window flame $(\mathrm{kW})$

$\dot{Q}_{B}$ Heat release rate $(\mathrm{kW})$

$\varepsilon \dot{Q}_{L} \quad$ Heat loss rate $(\mathrm{kW})$

$\dot{q}^{\prime \prime} \quad$ Heat flux $\left(\mathrm{kW} / \mathrm{m}^{2}\right)$

$Q^{\prime \prime}$ Cumulative heat absorbed per unit surface area $\left(\mathrm{kJ} / \mathrm{m}^{2}\right)$

$s \quad$ Distance between gravitational points of window flame and exterior wall (m)

$T \quad$ Temperature (K) 
$T_{P} \quad$ Pyrolysis temperature (K)

$\Delta T$ Temperature rise (K)

$t$ Time (s)

$U_{\infty}$ Wind velocity $(\mathrm{m} / \mathrm{s})$

$u_{0} \quad$ Maximum vented velocity of hot gas at the opening $(\mathrm{m} / \mathrm{s})$

$V \quad$ Volume of compartment $\left(\mathrm{m}^{3}\right)$

$w_{F}$ Density of movable combustible $\left(\mathrm{kg} / \mathrm{m}^{2}\right)$

$Y \quad$ Mass fraction rate of chemical species (-)

$Z_{N}$ Height of neutral plane (m)

\section{Greeks}

$\alpha$ Mass flow rate coefficient (-)

$\alpha_{B}$ Constant invoked in Eqn.(37) (-)

$\alpha_{F}$ Heat growth rate $\left(\mathrm{m}^{2} / \mathrm{s}^{2}\right)$

$\beta_{B}$ Constant invoked in Eqn.(41) $\left(\mathrm{kJ}^{-1)}\right.$

$\varepsilon \quad$ Emissivity (-)

$\theta \quad$ Angle (rad)

$\mu \quad$ Mean value

$\pi \quad$ Circumference ratio (-) 
$\rho$ Density $\left(\mathrm{kg} / \mathrm{m}^{3}\right)$

$\sigma$ Stefan-Boltzmann constant $\left(\mathrm{kW} / \mathrm{m}^{2} \mathrm{~K}^{4}\right)$, standard deviation

$\chi_{R}$ Rate of heat loss due to radiation (-)

$\Psi \quad$ Deficit rate of structural member due to burn-through (-)

$\Psi_{0}$ Rate of initial exposed surface area of fixed combustible (-)

$\Omega$ Dimensionless number defined in Eqn.(35) (-)

\section{Suffix}

$B \quad$ Firebrand

cr Critical for ignition

$D$ Opening

F Combustible, gasified fuel

$f l$ window flame

floor Floor

L Movable combustible

$M$ Compartment boundary, fixed combustible

$O$ Oxygen

$P \quad$ Firebrand

$R$ Thermal radiation 
standard ISO-834 standard fire curve

$T$ Interior surface of compartment

$\infty$ Reference, Ambient

\section{REFERENCES}

[1] Lyons PR, Fire in America, National Fire Protection Association, 1976.

[2] Dracket P, The book of Great Disaster, Purnell and Sons, 1977.

[3] Scawthorn C, Eidinger JM, Fire Following Earhquake, ASCE Publications, 2005.

[4] Japan Association for Fire Science and Engineering edited, Handbook of Fire, Kyoritsu Publishing, 1997. (in Japanese)

[5] Hamada M, On The Rate of Fire Spread, Disaster Research, Non-life Insurance Rating Organization of Japan, 1951; 1: 35-44. (in Japanese)

[6] Horiuchi S, Fire Protection of Buildings, Asakura Publishing, 1972. (in Japanese)

[7] Fujita T, Fire Spread Model and Numerical Simulation, Disaster Research., Non-life

Insurance Rating Organization of Japan, 1975; 8: 380-393. (in Japanese)

[8] Development of Countermeasures against Urban Fire, Project Report of The Integrated Technology Development, Ministry of Construction, 1982. (in Japanese)

[9] Yasuno K, Takai H, Namba Y, A Basic Study on Fire Spread Formula of Houses used by 
Logistic Curve, Transaction of Architectural Institute of Japan, 1982; 311: 137-144. (in Japanese)

[10] Investigation on The Cause Spread Behaviors of Post-Earthquake Fire and Its

Countermeasures, Report of Tokyo Fire Department, 1997. (in Japanese)

[11] Itoigawa E, Tsukagoshi I, Stochastic Model for Fire Spread in Urban Area based on

Firebrands Effect, J City Planning Institute of Japan, 1988; 23: 469-474. (in Japanese)

[12] Thomas GC, Cousins WJ, Lloydd DA, Heron DW, Mazzoni, Post-earthquake Fire Spread between Buildings Estimating and Costing Extent in Wellington, Proceedings 7th Symposium, International Association for Fire Safety Science, 2002; 691-702.

[13] Himoto K, Tanaka T, A Physically Based Model for Urban Fire Spread, Proceedings of 7th Symposium, International Association for Fire Safety Science, 2002; 129-140.

[14] Development of Hazard Assessment Method and Countermeasure Technology in Urban Planning, Project Report of The Integrated Technology Development, Ministry of Land, Infrastructure, and Transport, 2003. (in Japanese)

[15] Himoto K, Tanaka T, An Evaluation of Fire Resistant Performance of Takayama Sanmachi

District based upon Fire Spread Simulation, Proceedings of Annual Meeting, Transaction of Architectural Institute of Japan, 2004; A2: 337-336. (in Japanese)

[16] Matsuyama K, Development of A Fire Model for The Performance-based Fire Safety 
Engineering and Its Application, Dr.Eng. Thesis, Tokyo Univ. Sci., 2000. (in Japanese)

[17] Architectural Institute of Japan, Handbook of Building Design, Vol.1-Environment, Maruzen Publishing, 1978. (in Japanese)

[18] Himoto K, Tsuchihashi T, Tanaka Y, Tanaka T, Modeling Thermal Behaviors of Window Flame Ejected from A Fire Compartment, Fire Safety Journal. (submitted)

[19] Himoto K, Tsuchihashi T, Tanaka Y, Tanaka T, Modeling Trajectory of Window Flame with Regard to The Flow Attachment to The Adjacent Wall, Fire Safety Journal. (submitted)

[20] Quintiere J, Grove B, A unified Analysis for Fire Plumes, Proceedings 27th Symposium (Int.) on Combustion, The Combustion Institute, 1998; 2757-2766.

[21] Yokoi S, Temperature Distribution in The Downwind of A Line Fire, Disaster Research, Non-life Insurance Rating Organization of Japan, 1970; 7: 151-159. (in Japanese)

[22] Tsuchihashi T, Tasaka S, Yoshida M, Tanaka T, Estimation of Temperature Rise when Exposed to Plumes of Multiple Heat Sources, Proceedings Annual Meeting, Transaction of Architectural Institute of Japan, 2000; A2: 13-14. (in Japanese)

[23] Himoto K, Tanaka T, Transport of Disk-shaped Firebrand in A Turbulent Boundary Layer, Proceedings 8th Symposium, International Association for Fire Safety Science, 2005; 433-444.

[24] Yoshioka H, Hayashi H, Masuda H, Noguchi T, Real-Scale Fire Wind Tunnel Experiment on Generation of Firebrands from a House on Fire, Fire Science and Technology, 2004; 23-2: 
$142-151$

[25] Fire Spread Behaviors of The Sakata Fire, Technical Report of National Research Institute of Fire and Disaster, 1977. (in Japanese)

\section{List of Tables}

Table 1. Overview of the hypothetical urban area.

Table 2. Building types and their combustion properties.

Table 3. Parameters for the fire spread simulation.

Table 4. Outline of the Sakata Fire.

\section{List of Figures}

Fig.1. Schematic of the urban fire spread model.

Fig.2. Formation of a new opening due to the burn-through of compartment boundary.

Fig.3. Thermal radiation heat transfer from an window flame.

Fig.4. Fire plume blown down by the wind.

Fig.5. Probability of firebrand scattering released from a fire involved building.

Fig.6. Elevation of the assumed building and its spacing between adjacent buildings.

Fig.7. Results of fire spread simulation. 
Fig.8. Time vs. distance of fire spread when $U_{\infty}=2.5 \mathrm{~m} / \mathrm{s}$.

Fig.9. Time vs. distance of fire spread when $U_{\infty}=5.0 \mathrm{~m} / \mathrm{s}$.

Fig.10. Time vs. distance of fire spread when $U_{\infty}=10.0 \mathrm{~m} / \mathrm{s}$.

Fig.11. Bird's eye view of the burnt area looking from the west to the east.

Fig.12. Aerial photograph of the Sakata city.

Fig.13. Weather data recorded at the nearest meteorological station.

Fig.14. Result of fire spread simulation at 22:00, Oct. 29th.

Fig.15. Result of fire spread simulation at 0:00, Oct. 30th.

Fig.16. Result of fire spread simulation at 2:00, Oct. 30th.

Fig.17. Comparison of recorded and simulated fire spread. 
Table 1. Overview of the hypothetical urban area.

\begin{tabular}{|c|c|}
\hline Number of buildings & $2,500(-)$ \\
\hline Side length of a building $(a)$ & $8(\mathrm{~m})$ \\
\hline Building separation $(d)$ & $4(\mathrm{~m})$ \\
\hline Area ratio of the opening to wall & $0.3(-)$ \\
\hline Fraction of the building- $\mathrm{A}\left(a^{\prime}\right)$ & $0.2(-)$ \\
\hline Fraction of the building-B $\left(b^{\prime}\right)$ & $0.4(-)$ \\
\hline Fraction of the building-C $\left(c^{\prime}\right)$ & $0.4(-)$ \\
\hline Wind velocity $\left(U_{\infty}\right)$ & $2.5, \quad 5.0, \quad 10.0(\mathrm{~m} / \mathrm{s})$ \\
\hline
\end{tabular}


Table 2. Building types and their combustion properties.

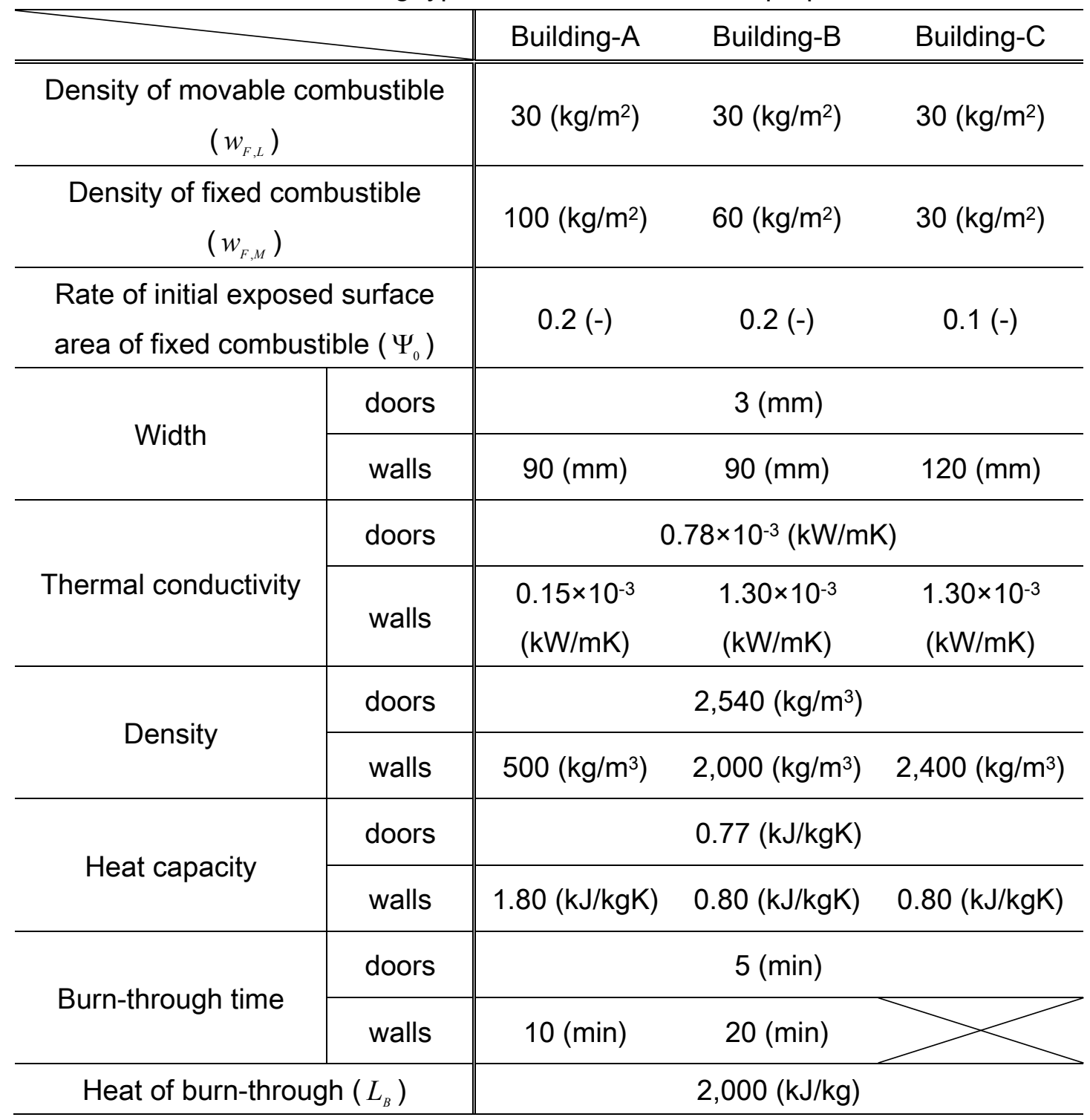


Table 3. Parameters for the fire spread simulation.

\begin{tabular}{cc}
\hline \hline Growth rate factor $\left(\alpha_{F}\right)$ & $1.0 \times 10^{-3}\left(\mathrm{~m}^{2} / \mathrm{s}^{2}\right)$ \\
\hline Heat of combustion for gasified fuel $\left(\Delta H_{F}\right)$ & $17,000(\mathrm{~kJ} / \mathrm{kg})$ \\
\hline Heat of combustion for oxygen $\left(\Delta H_{o}\right)$ & $13,100(\mathrm{~kJ} / \mathrm{kg})$ \\
\hline Rate of radiation heat loss $\left(\chi_{R}\right)$ & $0.3(-)$ \\
\hline Critical heat flux of ignition $\left(\dot{q}_{c r}^{\prime \prime}\right)$ & $15.0\left(\mathrm{~kW} / \mathrm{m}^{2}\right)$ \\
\hline Pyrolysis temperature of combustibles $\left(T_{P}\right)$ & $573(\mathrm{~K})$ \\
\hline Parameter on firebrand spotting $\left(\rho_{P} d_{P}\right)$ & $1.0\left(\mathrm{~kg} / \mathrm{m}^{2}\right)[21]$ \\
\hline Parameter on firebrand ignition $\left(\alpha_{B} \beta_{B}\right)$ & $0.0,1.0 \times 10^{-6}, 2.0 \times 10^{-6}\left(\mathrm{~kJ}^{-1}\right)$ \\
\hline
\end{tabular}


Table 4. Outline of the Sakata Fire.

\begin{tabular}{|c|c|}
\hline Date and time of the outbreak & 17:40, October 29th, 1976. \\
\hline Date and time of the control & 05:00, October 30th, 1976. \\
\hline Fire origin & $\begin{array}{l}\text { Initiated from a movie theater in the } \\
\text { downtown of Sakata. }\end{array}$ \\
\hline Cause of the fire & Unknown. \\
\hline \multirow{5}{*}{ Weather condition at the outbreak } & Rain; Intermittent rain showers, \\
\hline & Wind direction; WSW, \\
\hline & Wind velocity; $12.2 \mathrm{~m} / \mathrm{s}$ \\
\hline & Ambient temperature; $8.5^{\circ} \mathrm{C}$ \\
\hline & Relative humidity; $73 \%$. \\
\hline \multirow{2}{*}{ Burnt area } & Burnt site area; 22.5ha, \\
\hline & Burnt building area; $15.2 \mathrm{ha}$. \\
\hline Burnt buildings & $\begin{array}{l}1,744 \text { buildings were burnt, in which } \\
1,767 \text { of them were fully burnt and the } \\
\text { else were partly burnt. }\end{array}$ \\
\hline
\end{tabular}


Temperature rise due to wind blown fire plume

Firebrand spotting

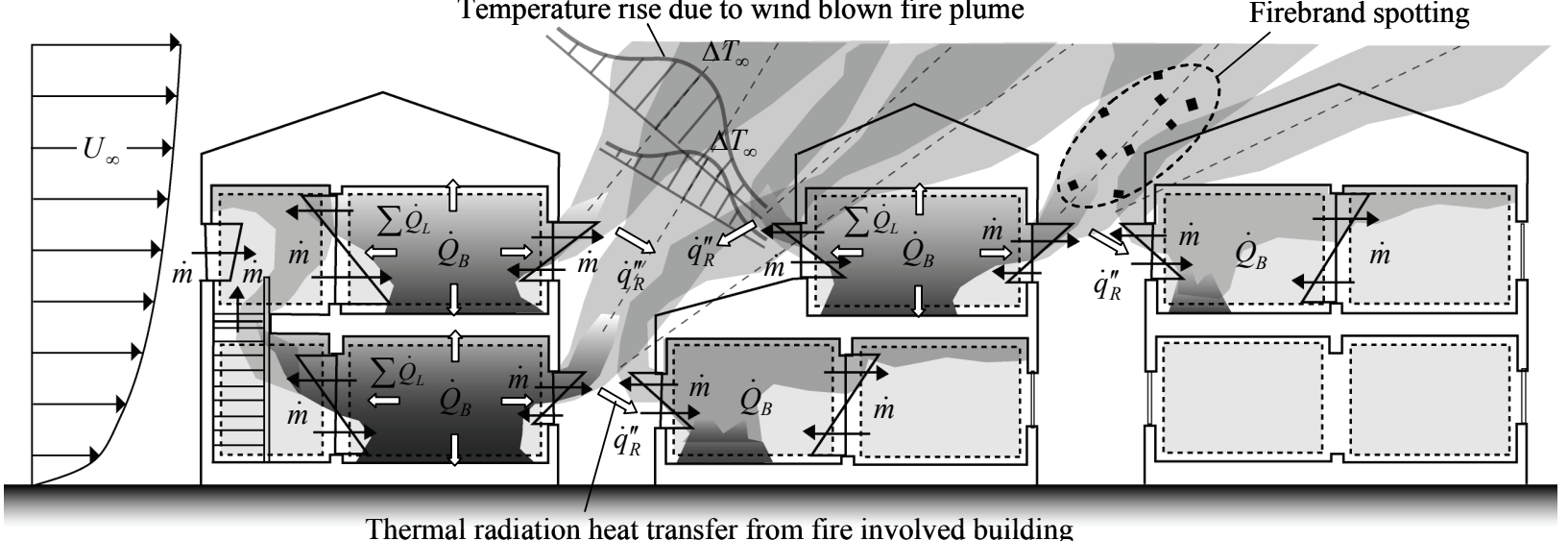

Thermal radiation heat transfer from fire involved building

Fig.1. Schematic of the urban fire spread model. 


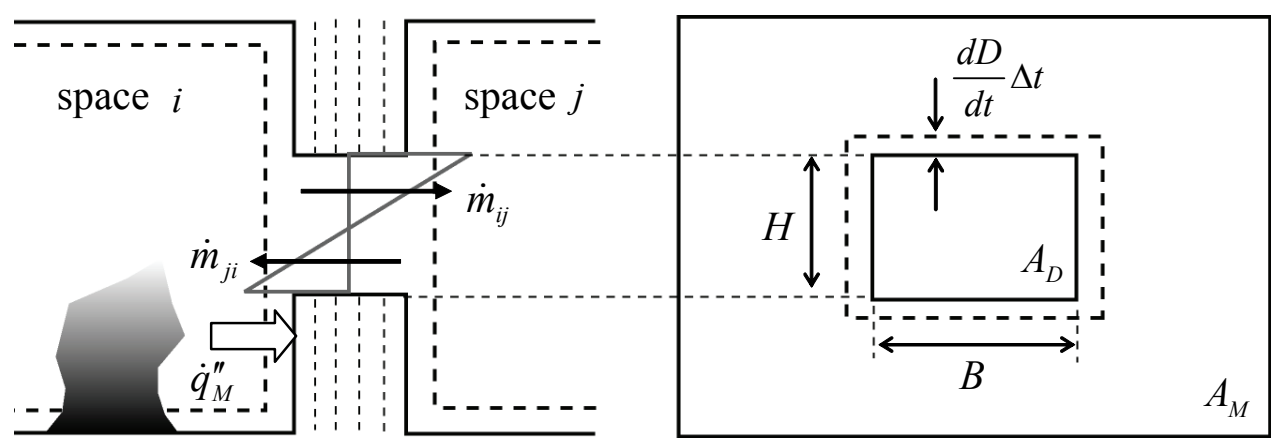

Fig.2. Formation of a new opening due to the burn-through of a compartment boundary. 


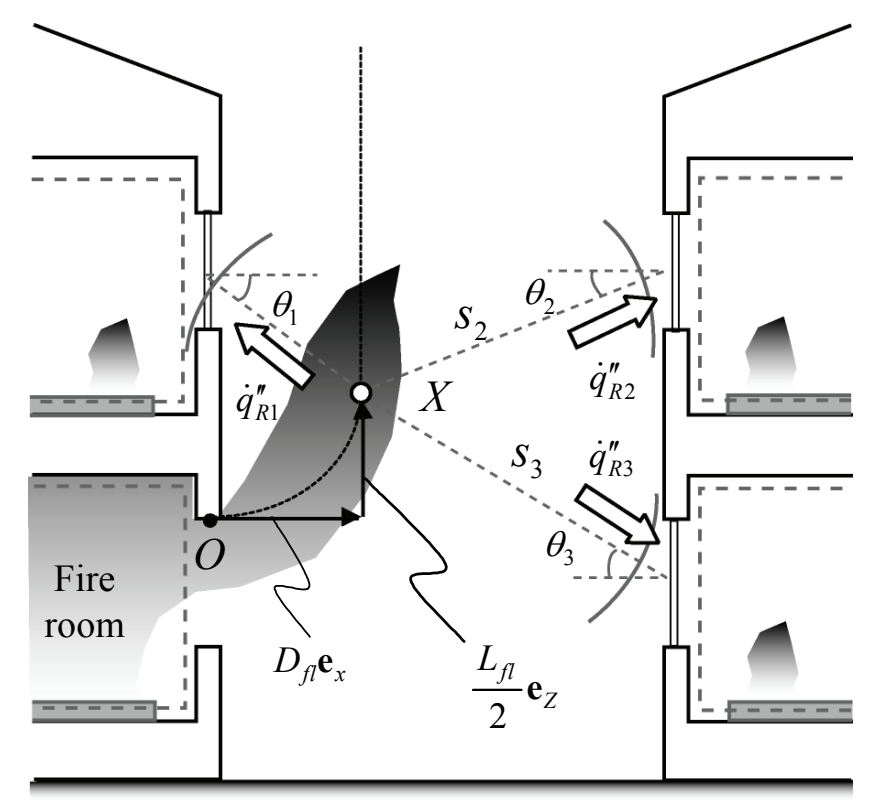

Fig.3. Thermal radiation heat transfer from an ejected flame. 


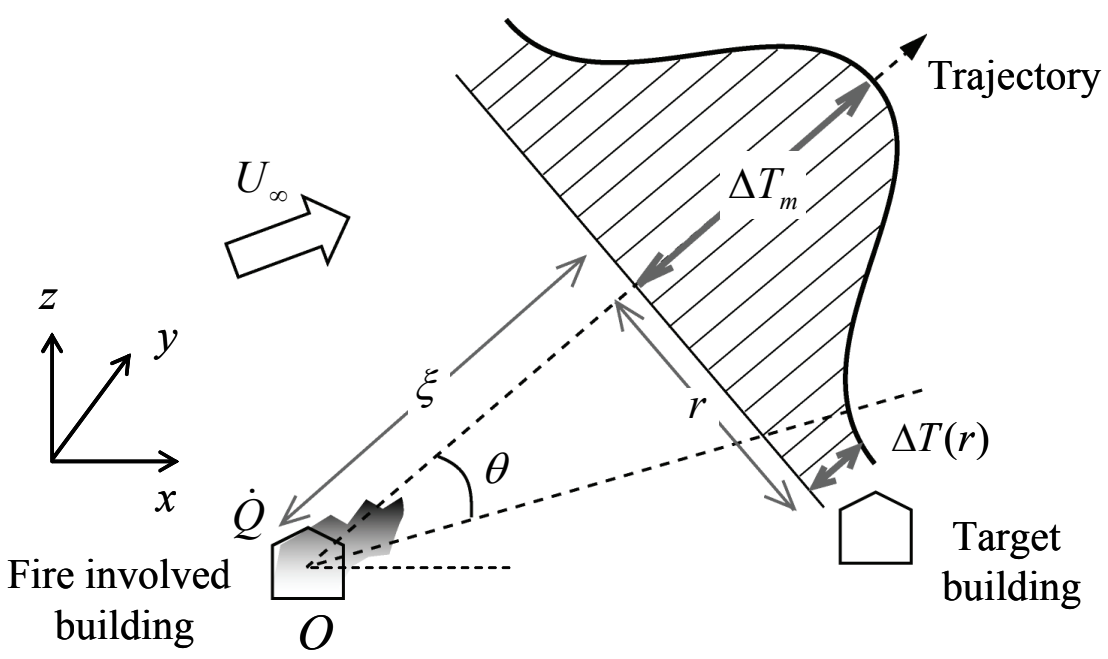

Fig.4. Fire plume blown down by the wind. 


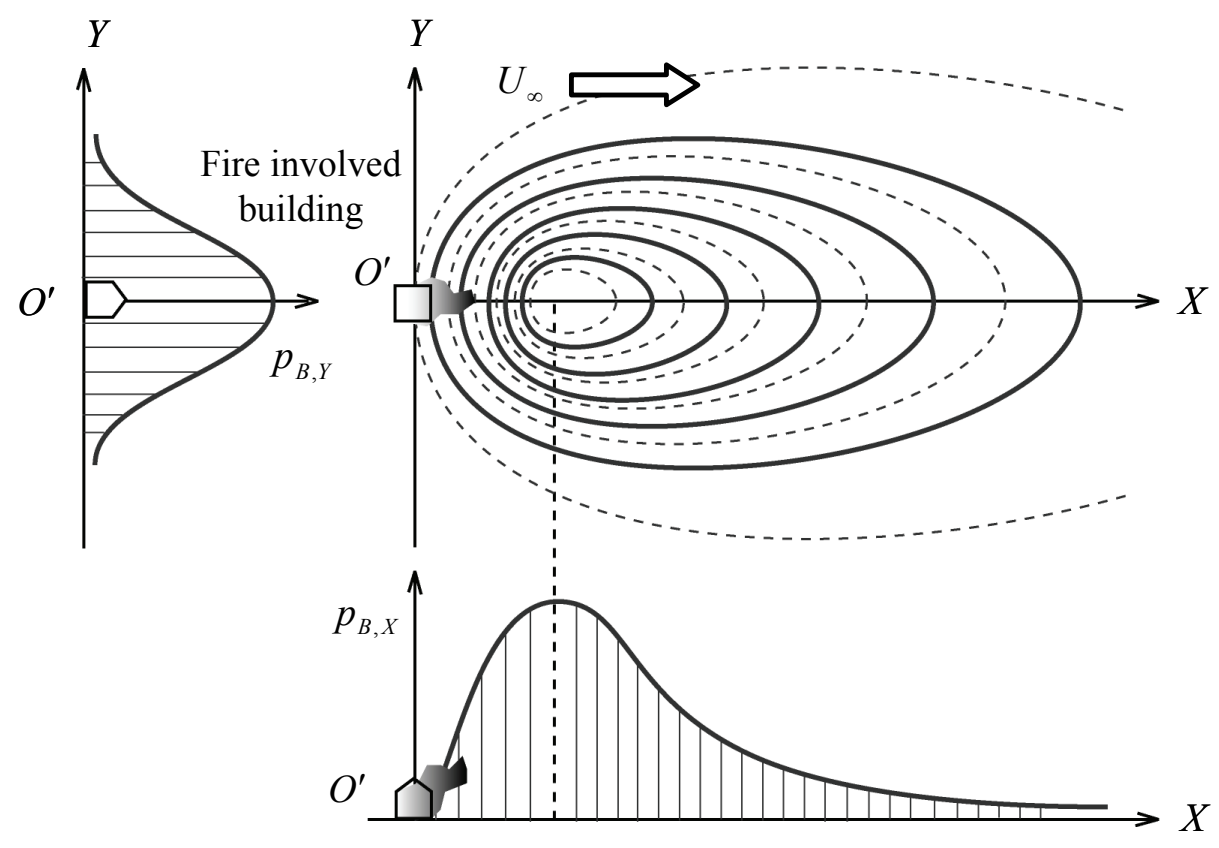

Fig.5. Probability of firebrand scattering released from a fire involved building. 


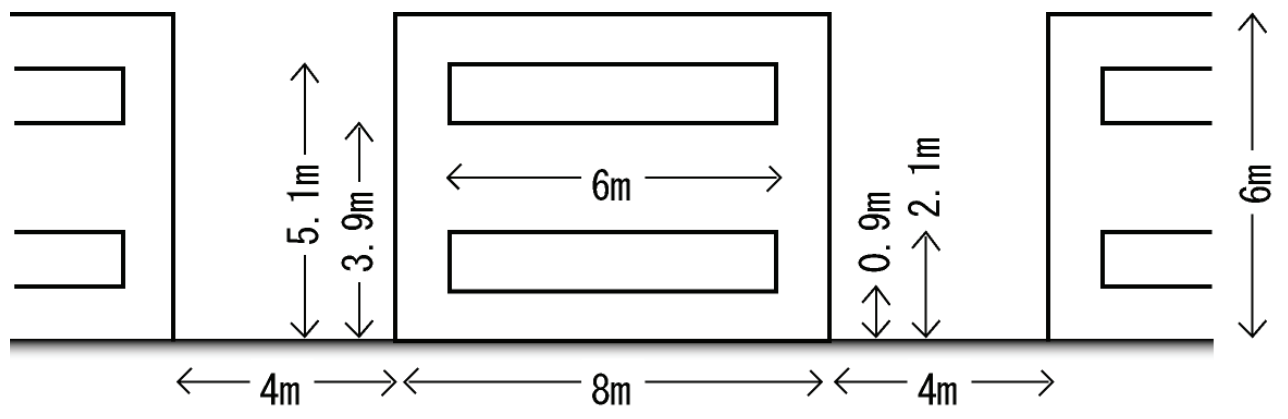

Fig.6. Elevation of the assumed building and its spacing between adjacent buildings. 

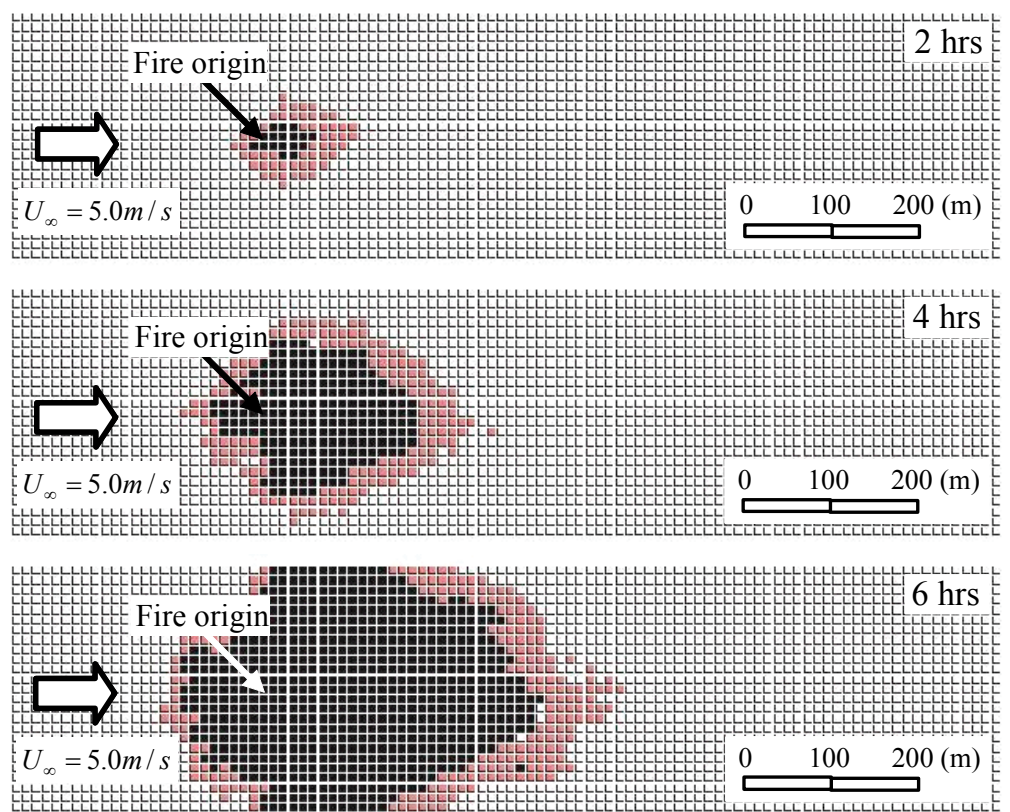

(A) $U_{\infty}=5.0 \mathrm{~m} / \mathrm{s}, \quad \alpha_{B} \beta_{B}=1.0 \times 10^{-6} \mathrm{~kJ}^{-1}$.
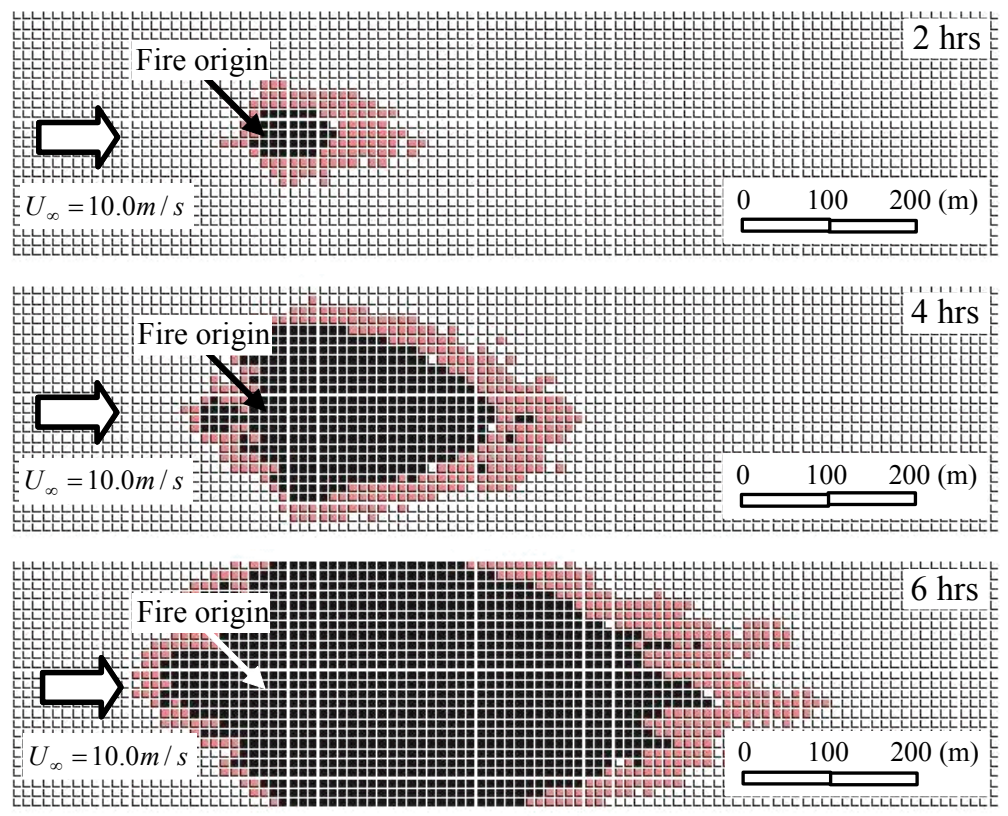

(B) $U_{\infty}=10.0 \mathrm{~m} / \mathrm{s}, \quad \alpha_{B} \beta_{B}=1.0 \times 10^{-6} \mathrm{~kJ}^{-1}$.

Fig.7. Results of fire spread simulation. Dark color and light color indicate burning buildings and burnt buildings respectively. 


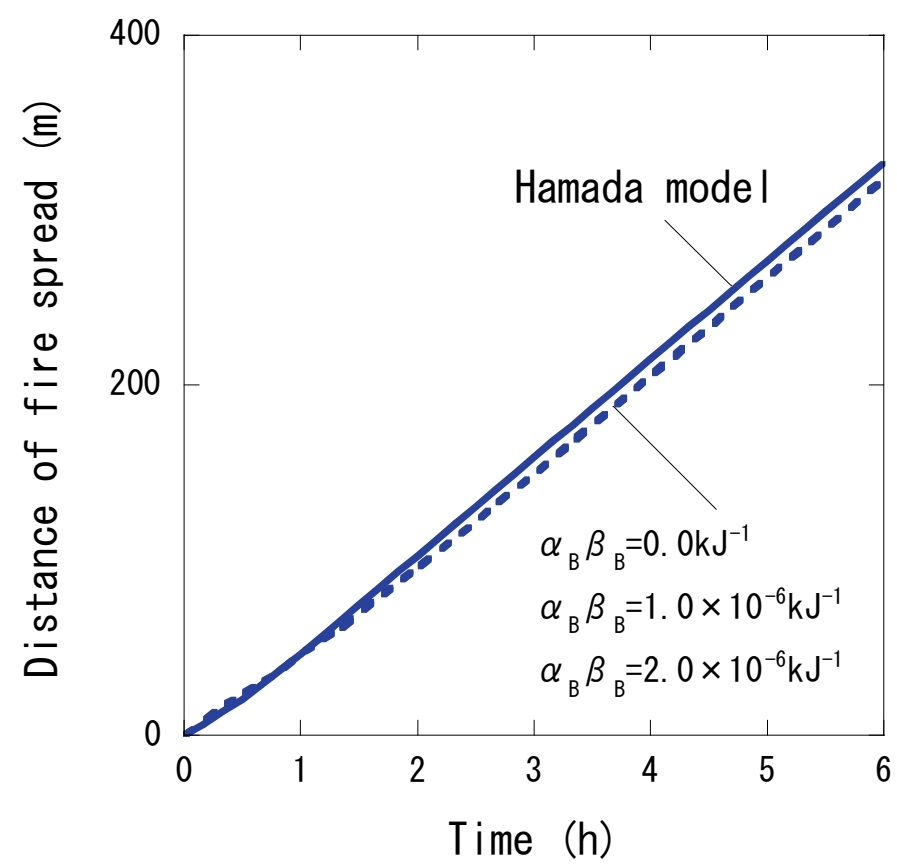

(A) Results for the downwind direction.

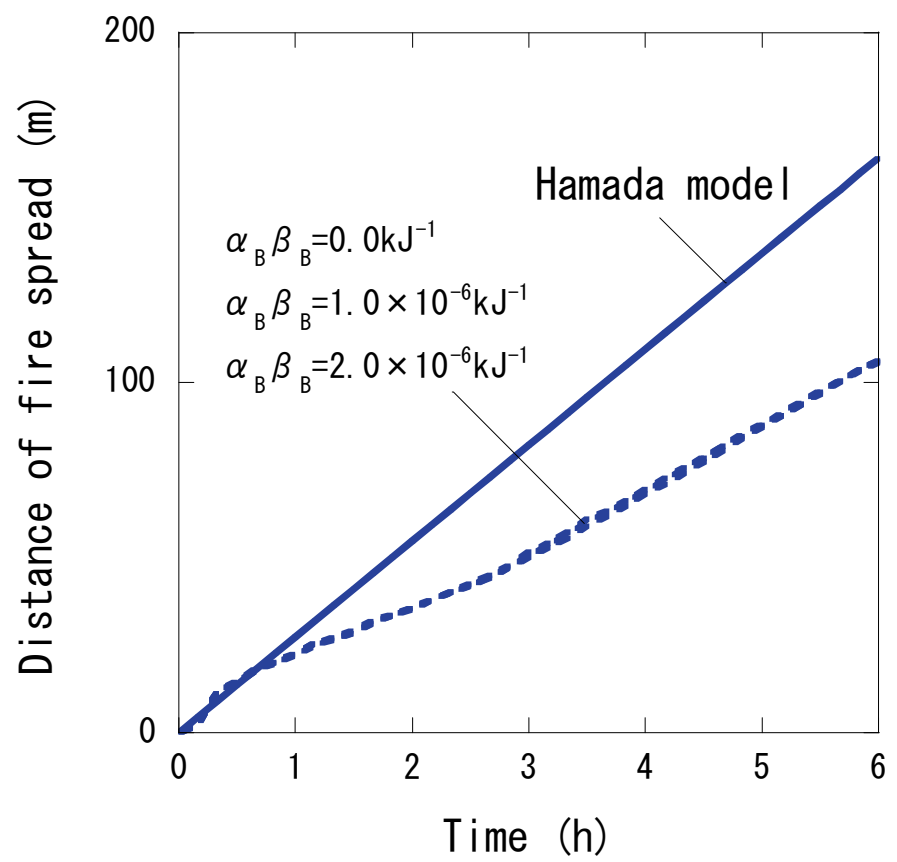

(B) Results for the upwind direction.

Fig.8. Time vs. distance of fire spread when $U_{\infty}=2.5 \mathrm{~m} / \mathrm{s}$. 


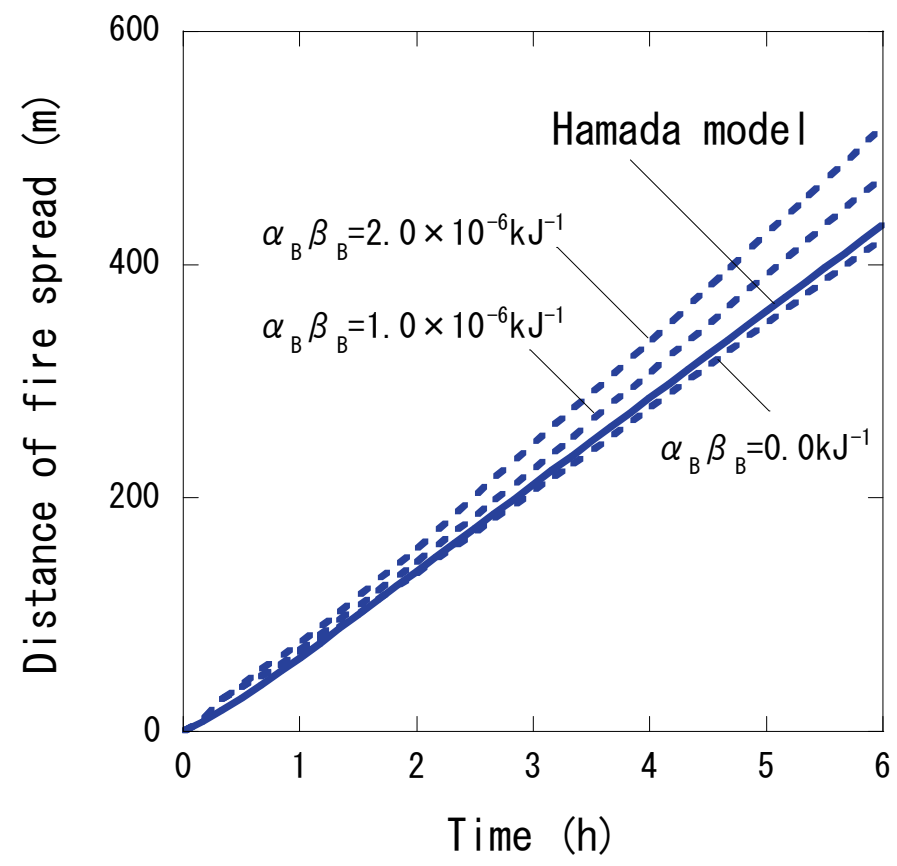

(A) Results for the downwind direction.

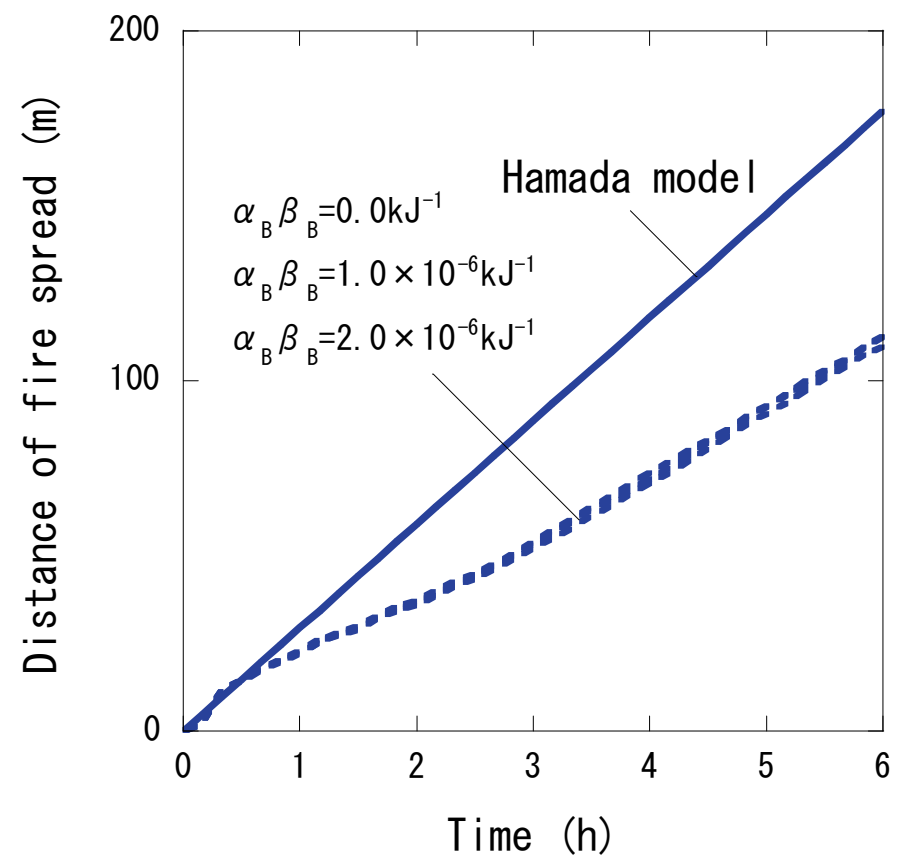

(B) Results for the upwind direction.

Fig.9. Time vs. distance of fire spread when $U_{\infty}=5.0 \mathrm{~m} / \mathrm{s}$. 


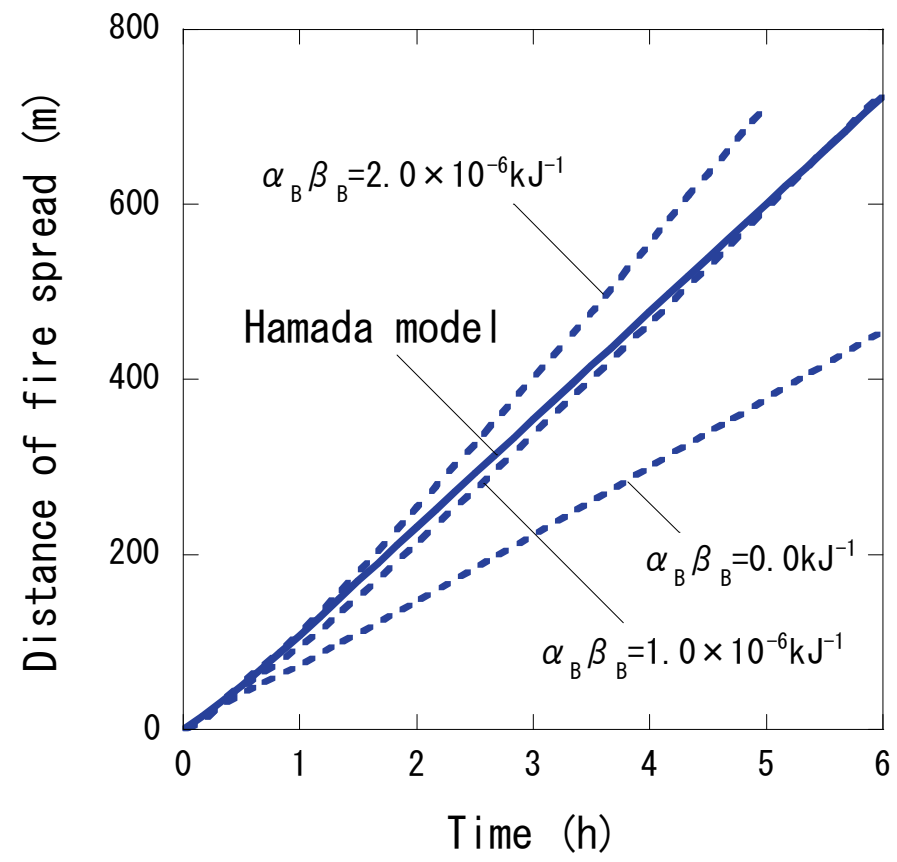

(A) Results for the downwind direction.

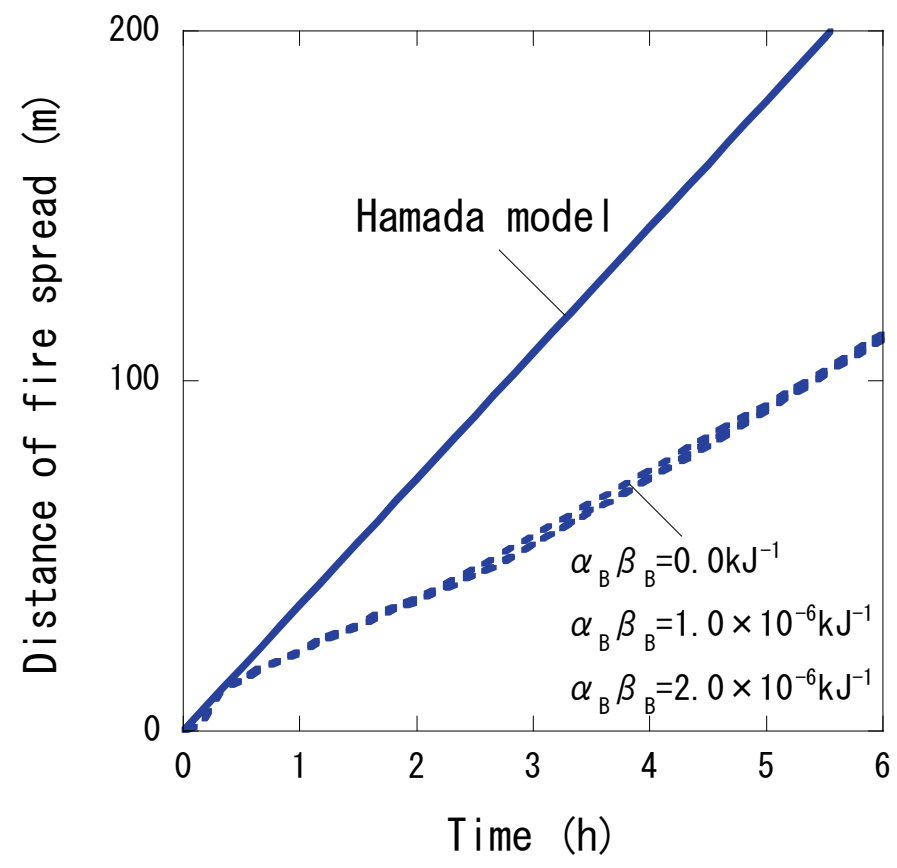

(B) Results for the upwind direction.

Fig.10. Time vs. distance of fire spread when $U_{\infty}=10.0 \mathrm{~m} / \mathrm{s}$. 


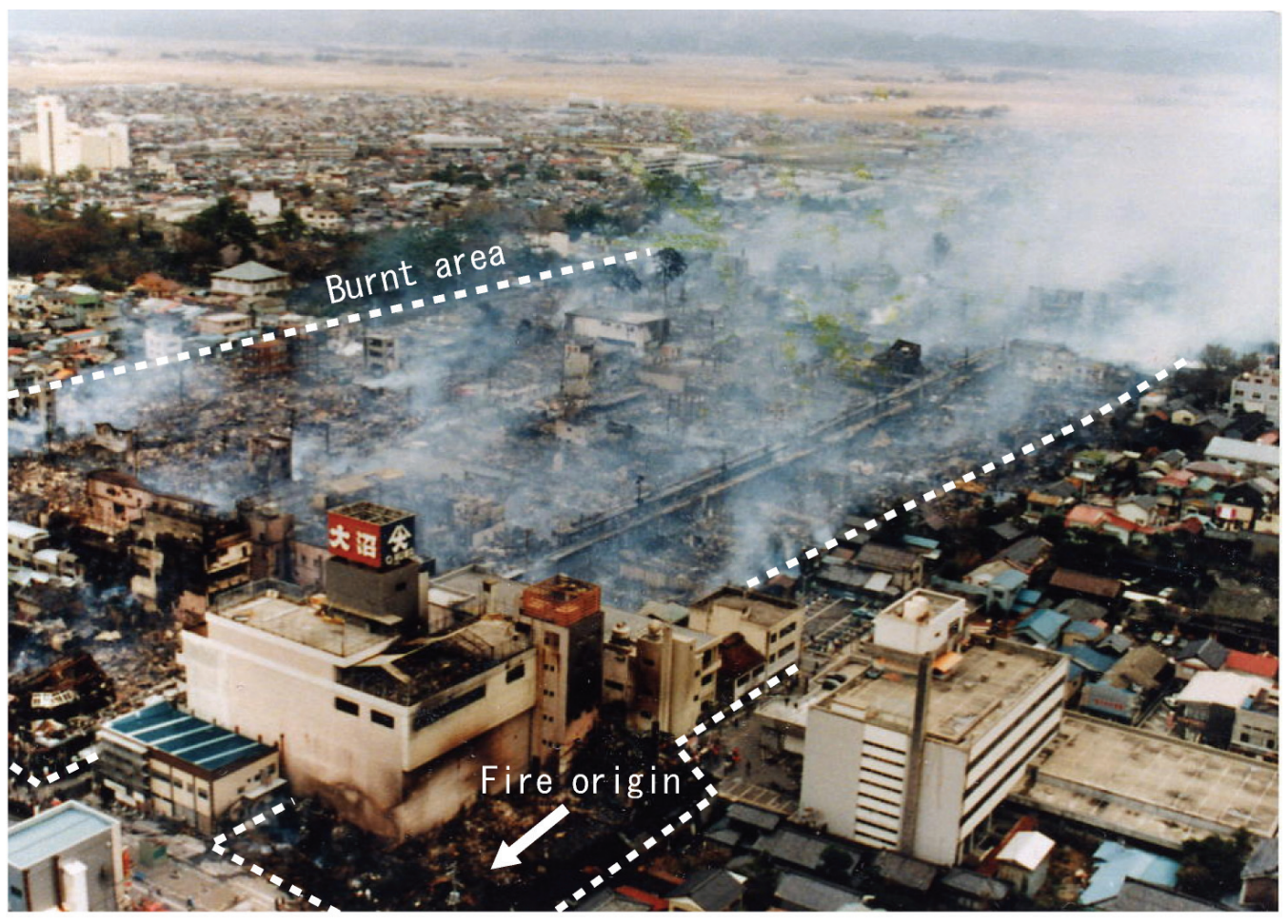

Fig.11. Bird's eye view of the burnt area looking from the west to the east. 


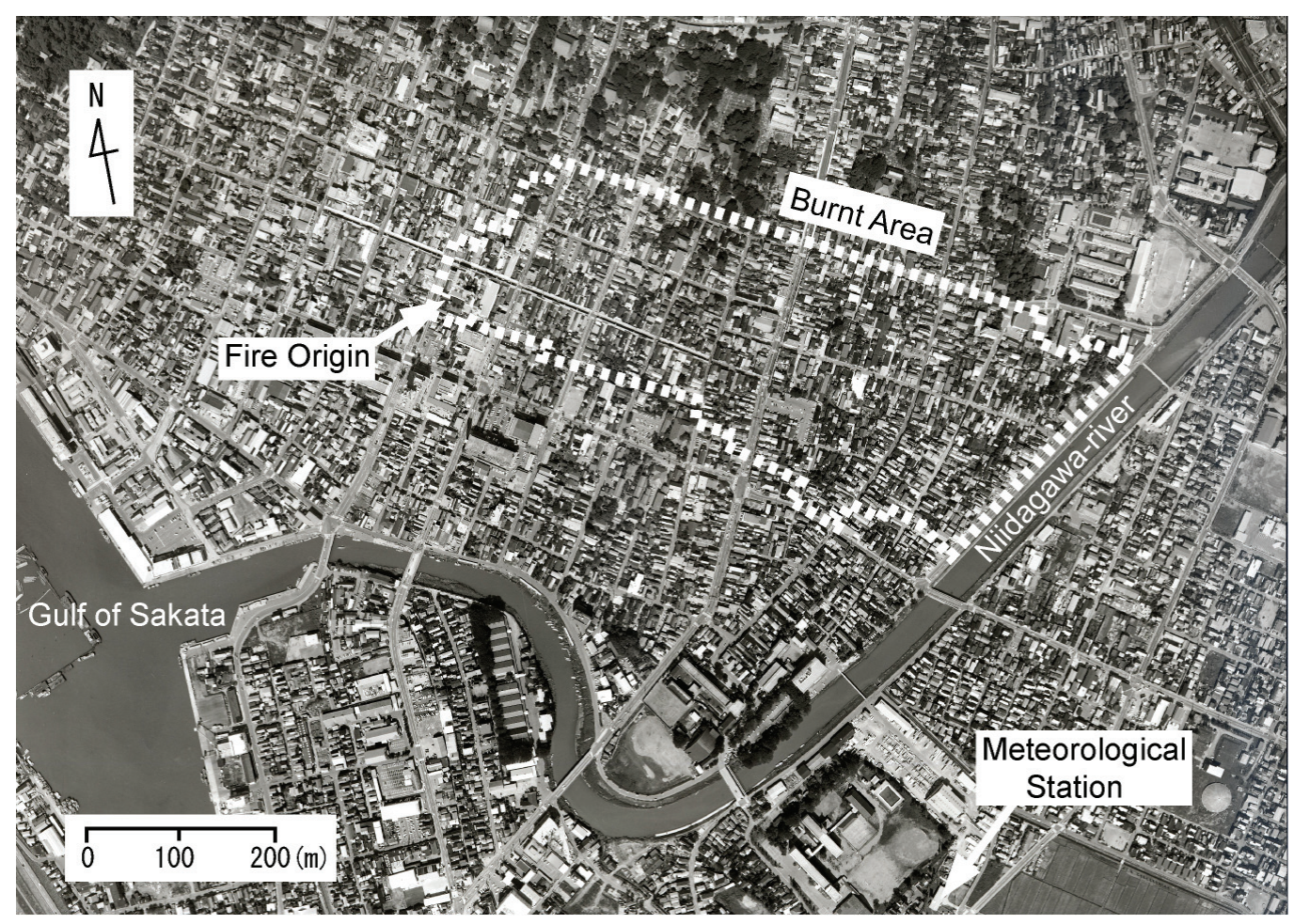

Fig.12. Aerial photograph of the Sakata city. 

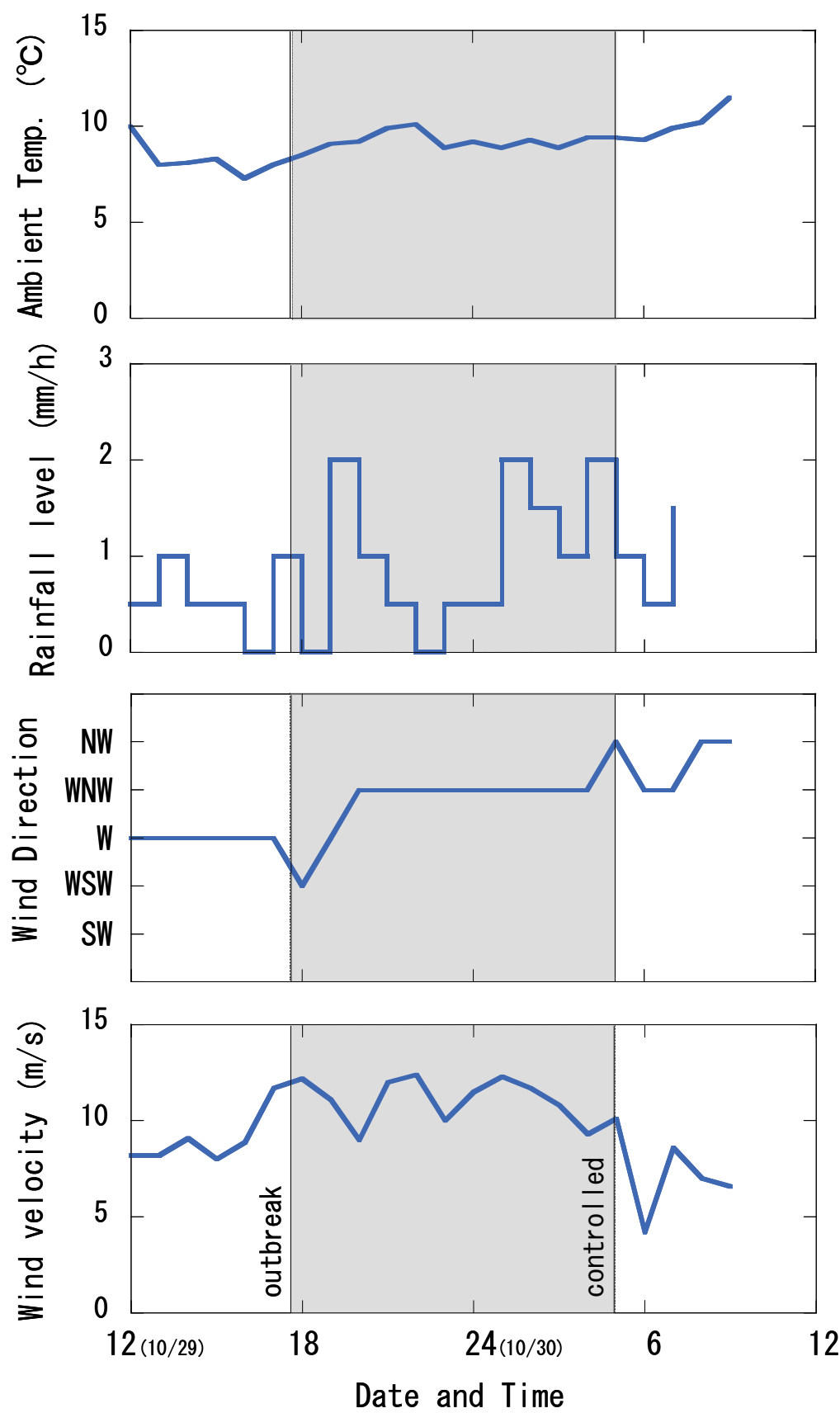

Fig.13. Weather data recorded at the nearest meteorological station. 


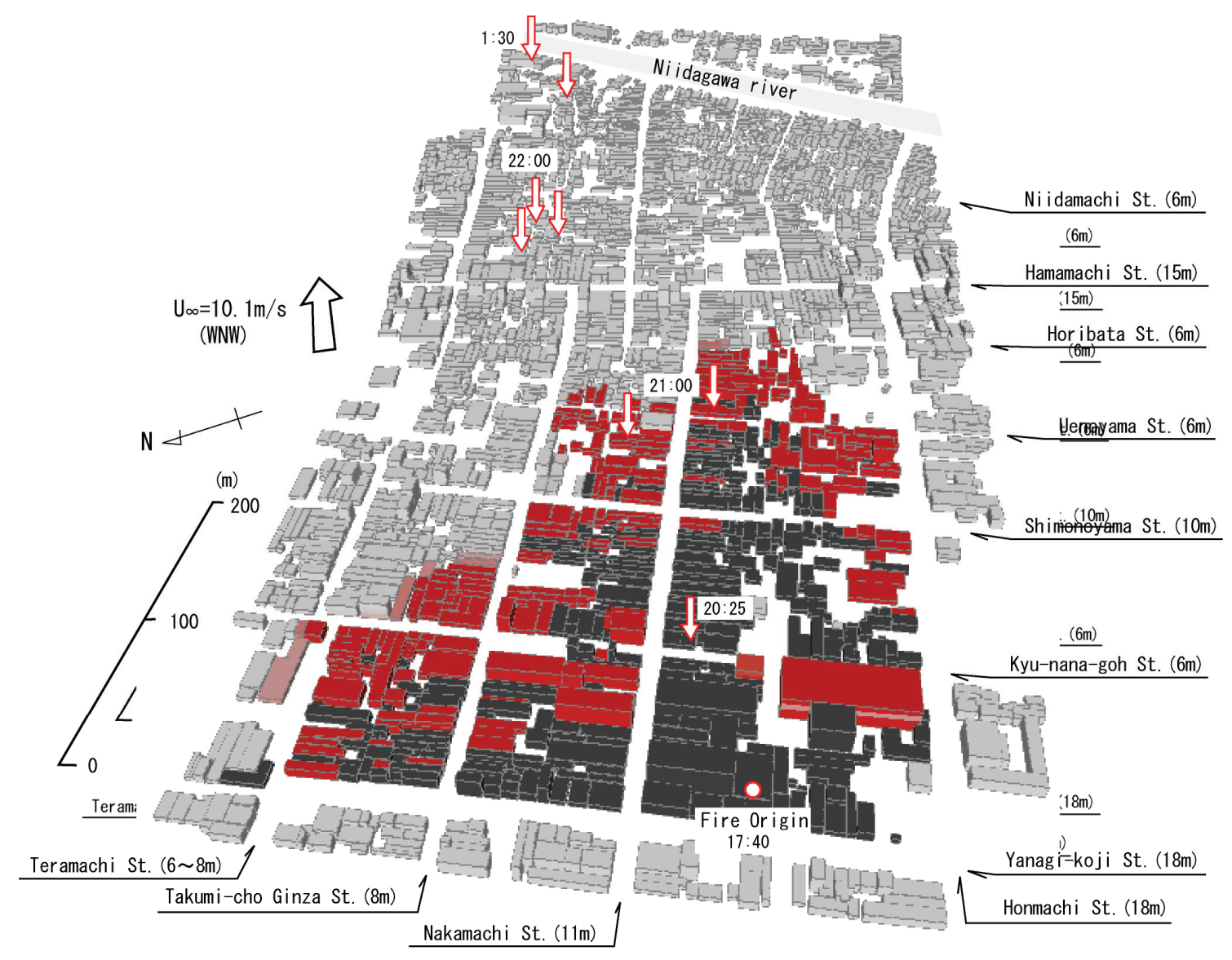

Fig.14. Result of fire spread simulation at 22:00 (4hrs 20min after the outbreak of fire), Oct. 29th. Arrows indicate buildings of secondary fire origin initiated by firebrands. 


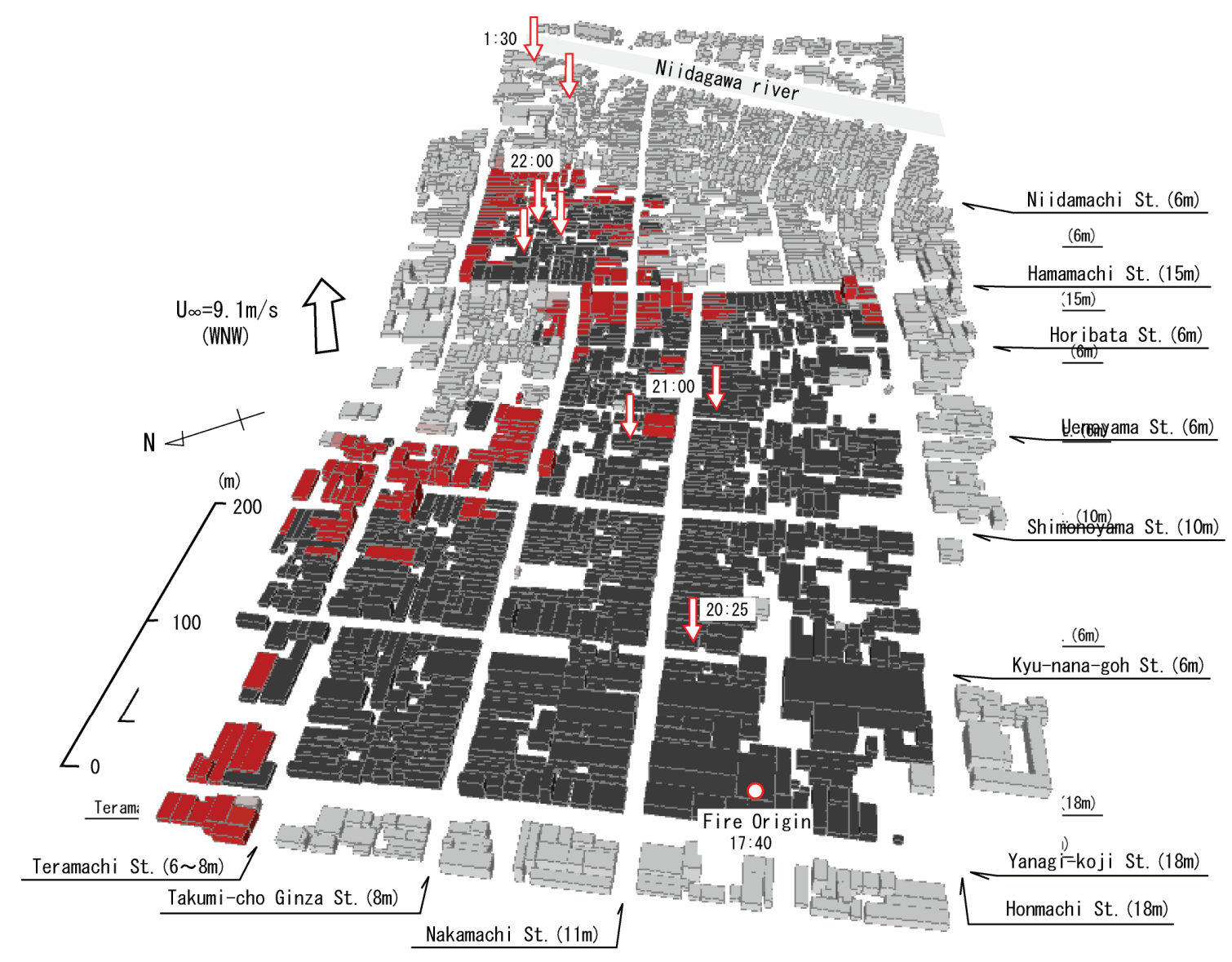

Fig.15. Result of fire spread simulation at 0:00 (6hrs 20min after the outbreak of fire), Oct. 30th. Arrows indicate buildings of secondary fire origin initiated by firebrands. 


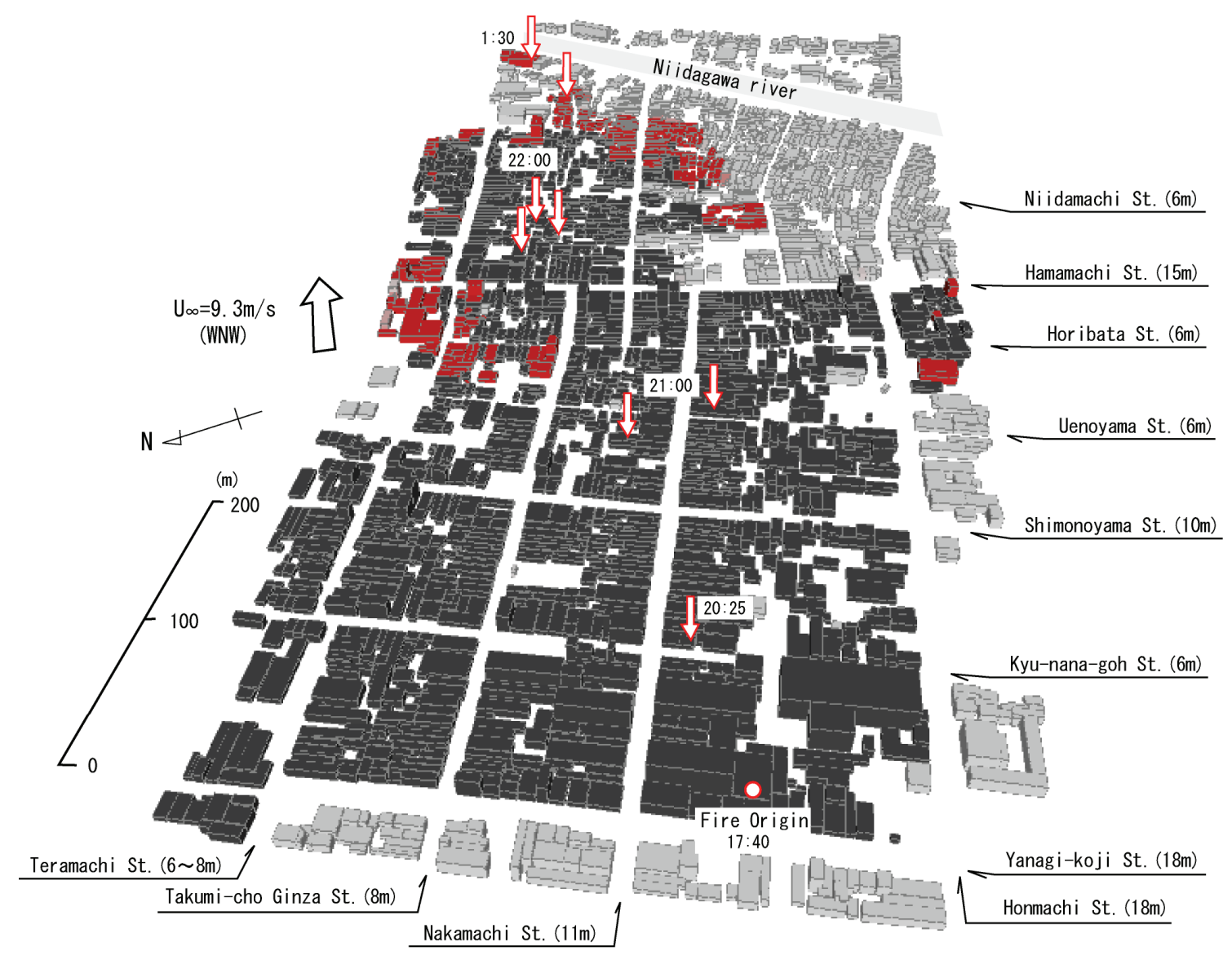

Fig.16. Result of fire spread simulation at 2:00 ( $8 \mathrm{hrs} 20 \mathrm{~min}$ after the outbreak of fire), Oct. 30th. Arrows indicate buildings of secondary fire origin initiated by firebrands. 


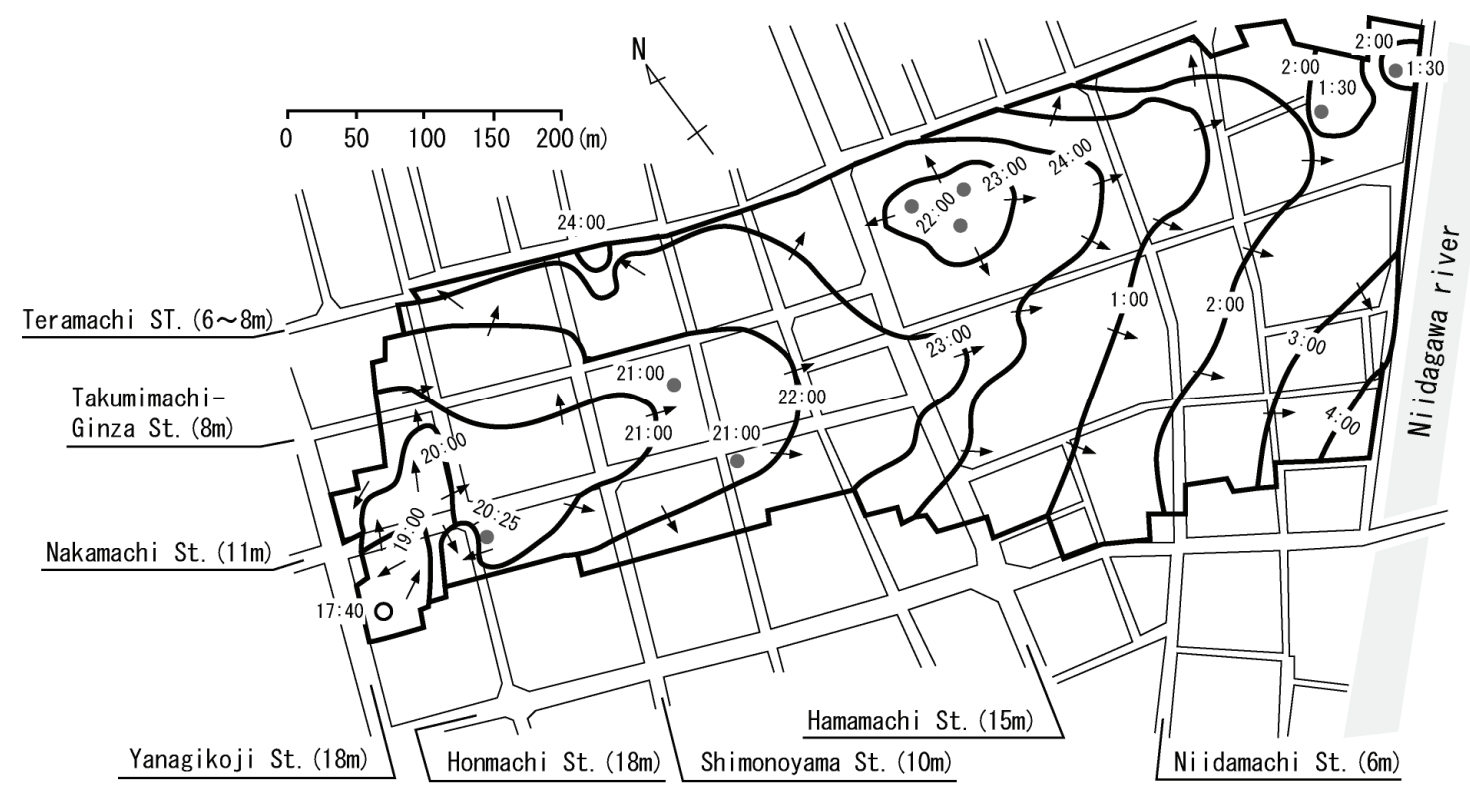

(A) Recorded fire spread.

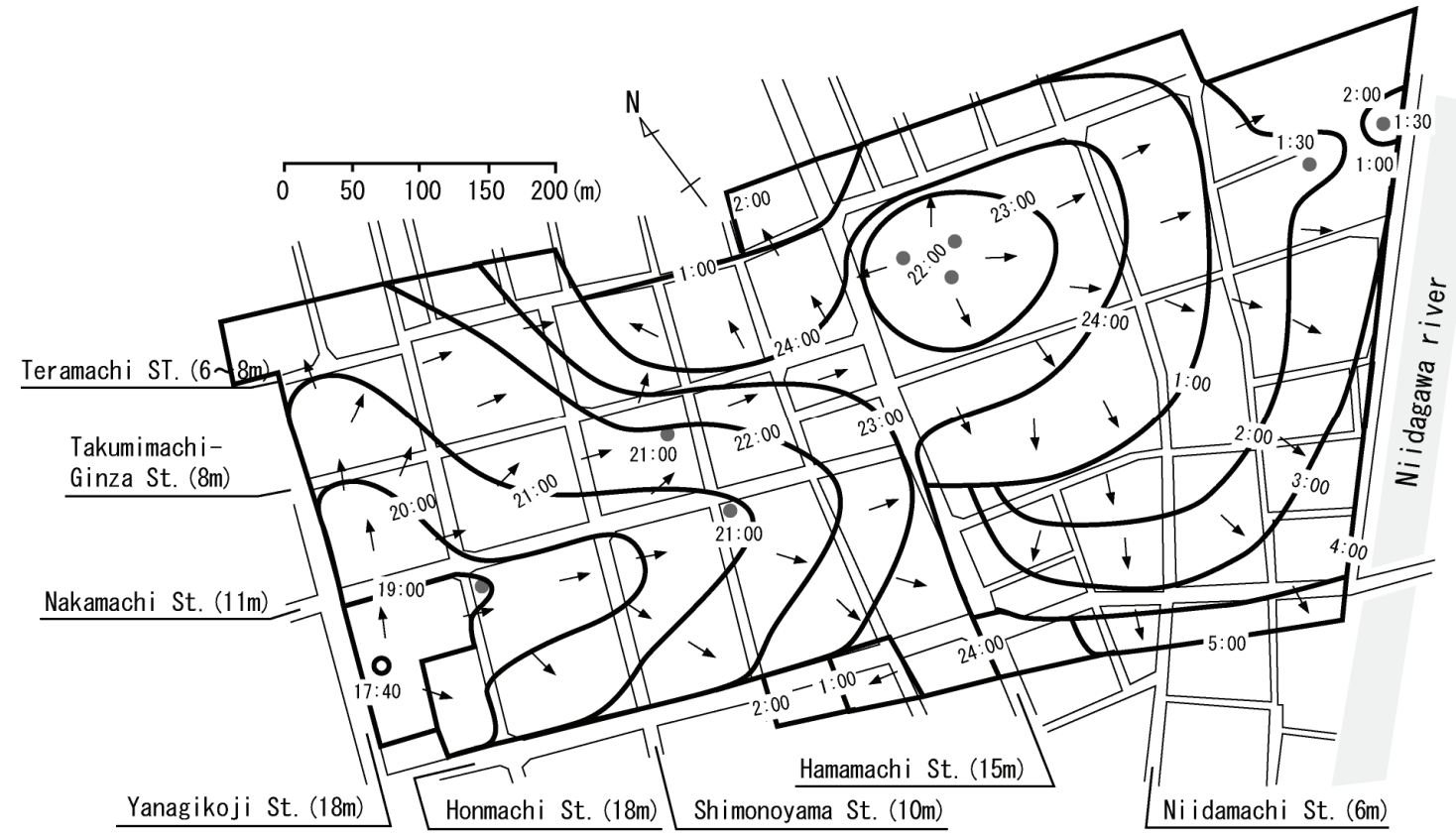

(B) Simulated fire spread.

Fig.17. Movement of fire front: closed circle ( $\mathrm{o}$ ) designates the fire origin and dots ( ) are the secondary fire origin caused by firebrands. 